Article

\title{
In Silico Screening of Semi-Synthesized Compounds as Potential Inhibitors for SARS-CoV-2 Papain-like Protease: Pharmacophoric Features, Molecular Docking, ADMET, Toxicity and DFT Studies
}

\author{
Mohamed S. Alesawy ${ }^{1}\left(\mathbb{D}\right.$, Eslam B. Elkaeed ${ }^{2} \mathbb{D}$, Aisha A. Alsfouk ${ }^{3} \mathbb{D}$, Ahmed M. Metwaly $^{4,5, *(\mathbb{D})}$ \\ and Ibrahim H. Eissa $1, *$ (D)
}

\section{check for} updates

Citation: Alesawy, M.S.; Elkaeed, E.B.; Alsfouk, A.A.; Metwaly, A.M.; Eissa, I.H. In Silico Screening of Semi-Synthesized Compounds as Potential Inhibitors for SARS-CoV-2 Papain-like Protease: Pharmacophoric Features, Molecular Docking, ADMET, Toxicity and DFT Studies. Molecules 2021, 26, 6593. https:// doi.org/10.3390/molecules26216593

Academic Editor: George Lambrinidis

Received: 13 September 2021

Accepted: 28 October 2021

Published: 30 October 202

Publisher's Note: MDPI stays neutral with regard to jurisdictional claims in published maps and institutional affiliations.

Copyright: (c) 2021 by the authors. Licensee MDPI, Basel, Switzerland. This article is an open access article distributed under the terms and conditions of the Creative Commons Attribution (CC BY) license (https:// creativecommons.org/licenses/by/ $4.0 /)$.
1 Pharmaceutical Medicinal Chemistry and Drug Design Department, Faculty of Pharmacy (Boys), Al-Azhar University, Cairo 11884, Egypt; mohammedalesawy@azhar.edu.eg

2 Department of Pharmaceutical Sciences, College of Pharmacy, Almaarefa University, Ad Diriyah, Riyadh 13713, Saudi Arabia; ikaeed@mcst.edu.sa

3 Department of Pharmaceutical Sciences, College of Pharmacy, Princess Nourah Bint Abdulrahman University, Riyadh 11671, Saudi Arabia; aaalsfouk@pnu.edu.sa

4 Pharmacognosy and Medicinal Plants Department, Faculty of Pharmacy (Boys), Al-Azhar University, Cairo 11884, Egypt

5 Biopharmaceutical Products Research Department, Genetic Engineering and Biotechnology Research Institute, City of Scientific Research and Technological Applications (SRTA-City), Alexandria 21934, Egypt

* Correspondence: ametwaly@azhar.edu.eg (A.M.M.); Ibrahimeissa@azhar.edu.eg (I.H.E.)

Abstract: Papain-like protease is an essential enzyme in the proteolytic processing required for the replication of SARS-CoV-2. Accordingly, such an enzyme is an important target for the development of anti-SARS-CoV-2 agents which may reduce the mortality associated with outbreaks of SARSCoV-2. A set of 69 semi-synthesized molecules that exhibited the structural features of SARS-CoV-2 papain-like protease inhibitors (PLPI) were docked against the coronavirus papain-like protease (PLpro) enzyme (PDB ID: (4OW0). Docking studies showed that derivatives 34 and 58 were better than the co-crystallized ligand while derivatives 17, 28, 31, 40, 41, 43, 47, 54, and 65 exhibited good binding modes and binding free energies. The pharmacokinetic profiling study was conducted according to the four principles of the Lipinski rules and excluded derivative 31. Furthermore, ADMET and toxicity studies showed that derivatives 28,34 , and 47 have the potential to be drugs and have been demonstrated as safe when assessed via seven toxicity models. Finally, comparing the molecular orbital energies and the molecular electrostatic potential maps of 28,34 , and 47 against the co-crystallized ligand in a DFT study indicated that $\mathbf{2 8}$ is the most promising candidate to interact with the target receptor (PLpro).

Keywords: COVID-19; papain-like protease; pharmacophore; molecular docking; ADMET; toxicity; DFT; semi-synthesized

\section{Introduction}

As of 10 September 2021, the uncontrolled SARS-CoV-2 had infected 222,406,582 and killed 4,592,934 people all over the world, according to the WHO [1]. The alarming spread necessitates contentious work until a cure is discovered. Computational (in silico, computer-aided, or cheminformatics) approaches have been used in various fields related to drug discovery [2], such as molecular docking [3-5], pharmacophore studies [6], drug molecular design [7,8], QSAR [9], toxicity prediction [10-12], ADMET assessment [13-15], and DFT calculations [16].

These approaches have been practiced fruitfully and frequently in several scientific studies to find a treatment against COVID-19 with the advantage of taking less effort, time, and cost [17-21]. 
Since the first historical records, people counted on natural sources around them to get food, cures, and even beauty tools $[22,23]$. Scientists authenticated the healing effects of plants [24,25] and, recently, microorganisms [26,27]. Plants and microorganisms naturally synthesize diverse chemical compounds as nitrogenous alkaloids [28], flavonoids [29,30], saponins [31,32], steroids [33], chromenes [34], $\alpha$-pyrones [35], diterpenoids [36] and sesquiterpenoids $[37,38]$.

More than $30 \%$ of FDA-approved drugs were based on natural products from 1981 to 2014 [39]. The main aim of the semi-synthesis approach in developing natural products is to obtain several analogs allowing the discovery of stronger drugs and even repurposing [40]. Additionally, it's much easier to conduct structure-activity relationship investigations, which gives the advantage of obtaining novel bioactive molecules and modifying druglikeness, pharmacodynamic and pharmacokinetic characteristics [41].

Papain-like protease (PLpro) is a pivotal enzyme in the coronavirus that has two major functions. The first one is included in the generation of an efficient replicase complex via the processing mechanism of viral polyproteins [42]. Additionally, the PLpro plays a vital role against the immunity of the host (human) via performing different cleaving modifications on the proteins of human immune responses [43]. Consequently, the inhibition of such a vital protein could be a great step toward finding a cure against COVID-19. Accordingly, we utilized PLpro as a potential target in our virtual screening

At Protein Data Bank, there are three crystal structures of coronavirus papain-like proteases (PLpro) with their co-crystallized ligands. The first crystal structure has the PDB ID of 3E9S, and the co-crystallized ligand is 5-amino-2-methyl- $N-[(1 \mathrm{R})-1$-naphthalen1-ylethyl]benzamide (TTT) I [44]. The second one has the PDB ID of 4OW0, and the co-crystallized ligand is N-[(3-fluorophenyl)methyl]-1-[(1R)-1-naphthalen-1-ylethyl] piperidine-4-carboxamide (S88) II [45]. The third one has the PDB ID of 7JIT, and the cocrystallized ligand is 5-[(carbamoylcarbamoyl)amino]-2-methyl- $N$-[(1R)-1-(naphthalen1-yl) ethyl]benz- amide (Y95) III [46]. The reported SARS-CoV-2 papain-like protease inhibitors (PLPIs) have the following four main pharmacophoric features: (1) aromatic system, (2) linker, (3) amide moiety, and (4) terminal hydrophobic region [47]. These features were satisfied in several PLPIs as shown in Figure 1. In the literature, compounds IV and V showed promising activity against Adenovirus, HSV-1, coxsackievirus, and SAR-CoV-2. In addition, these compounds showed a good binding mode against PLP. Furthermore, such compounds have the same features of PLP inhibitors [48].

A set of 69 semi-synthesized molecules (Figure 2) that have the essential features of SARS-CoV-2 PLPIs was downloaded from the Eximed laboratory website [49] and used in this research. The selected semi-synthesized molecules were screened against PLpro through docking studies. Figure 3 demonstrates the presence of those features in a representative sample of the examined semi-synthesized molecules. The examined molecules that showed a good binding modes and high-affinity values against PLpro were further in silico examined for their drug-likeness characters using the Lipinski rule of five, ADMET, and toxicity profiling. The most promising derivatives were subjected to DFT studies to get additional insight into their electron distribution. 


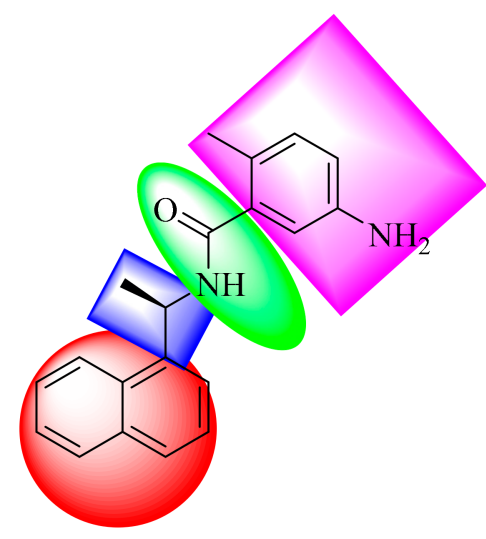

TTT (I)

PDB ID : 3E9S

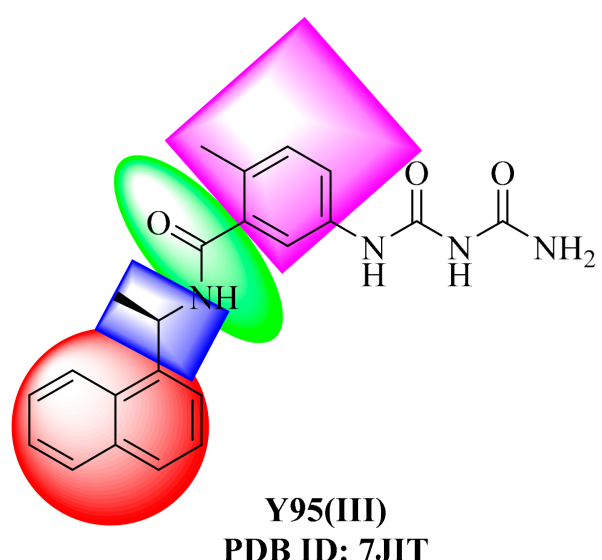

PDB ID: 7JIT

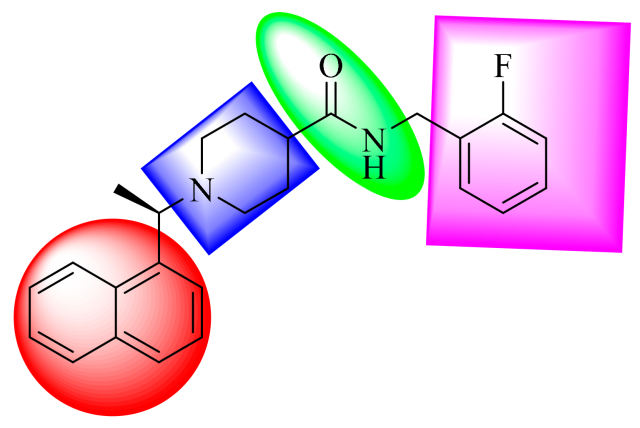

S88(II)

PDB ID: 4OW0

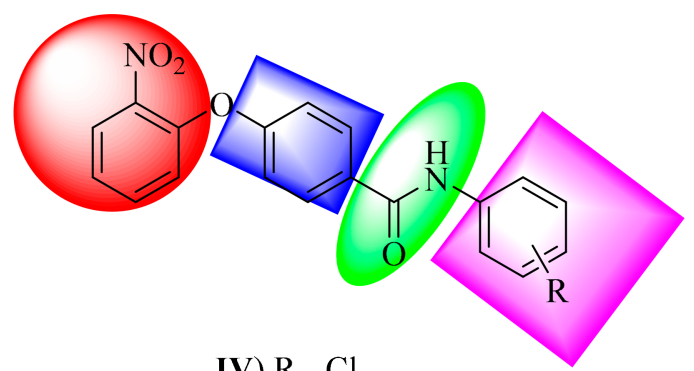

IV) $\mathrm{R}-\mathrm{Cl}$

V) $\mathrm{R}=\mathrm{CH}_{3}$

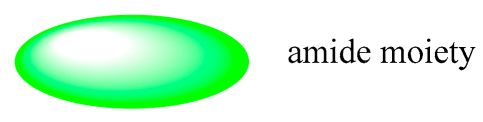

linker

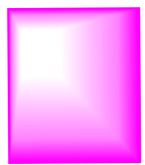

terminal hydrophobic region

Figure 1. Essential pharmacophoric features of SARS-CoV-2 PLPIs. 
(2)

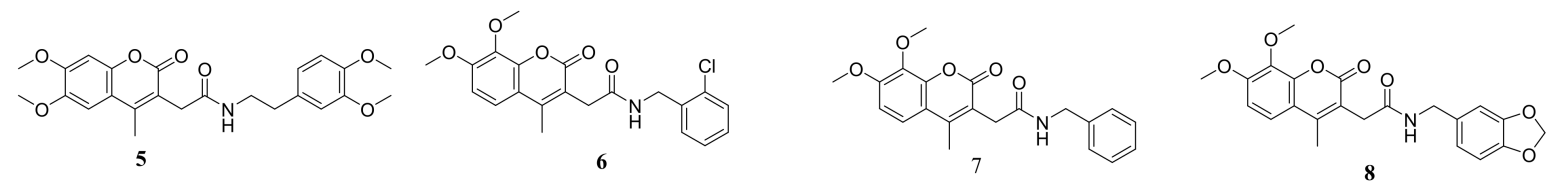
(1) (15) $\underbrace{O}_{17}$ $\overbrace{0}^{N_{21}^{\prime}}$

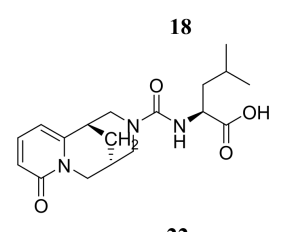

22

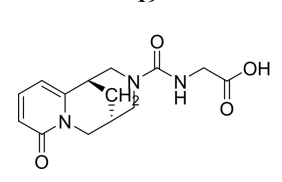

23
$\underbrace{N_{1}^{20}}_{0}$

24 (1)

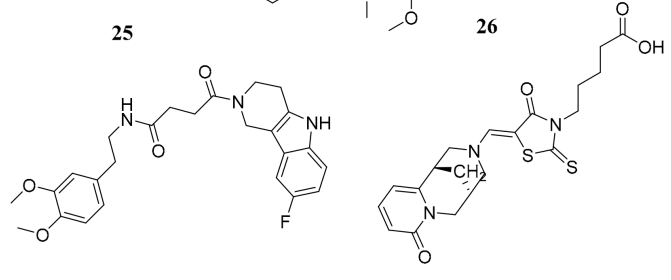

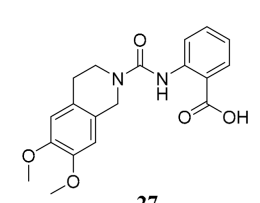

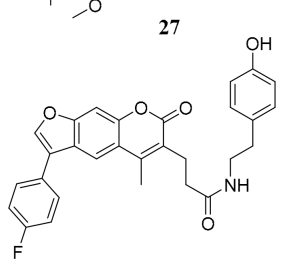

30

31<smiles>COc1ccc(CCNC(=O)CCC(=O)N2CC[C@H]3Cc4ccccc4C32)cc1OC</smiles>

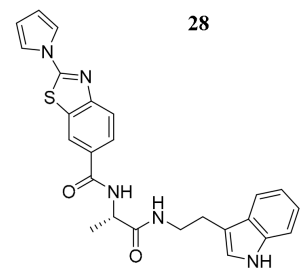

32

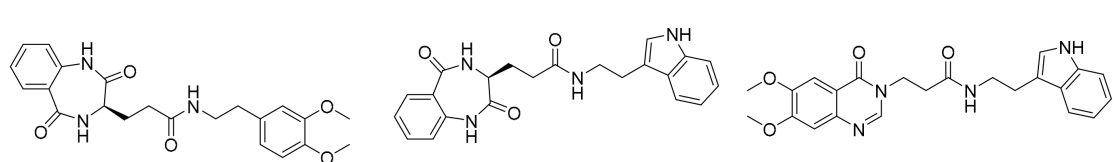
(1)

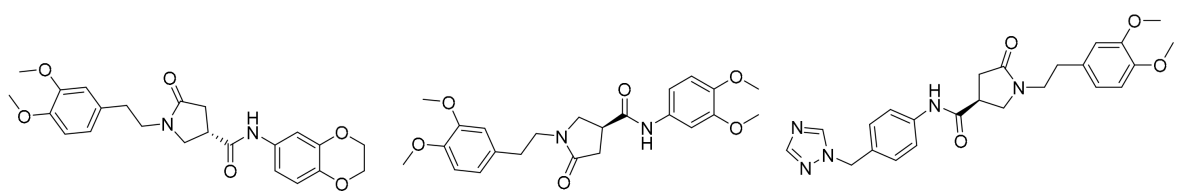
41 
(1) (1)

49

50

51

52

1)

53

54

55

56

(1)

(1)

61
62
63<smiles>O=C(CCNC(=O)N1CCc2c([nH]c3ccccc23)C1)N1CCN(c2cccc(Cl)c2)CC1</smiles>
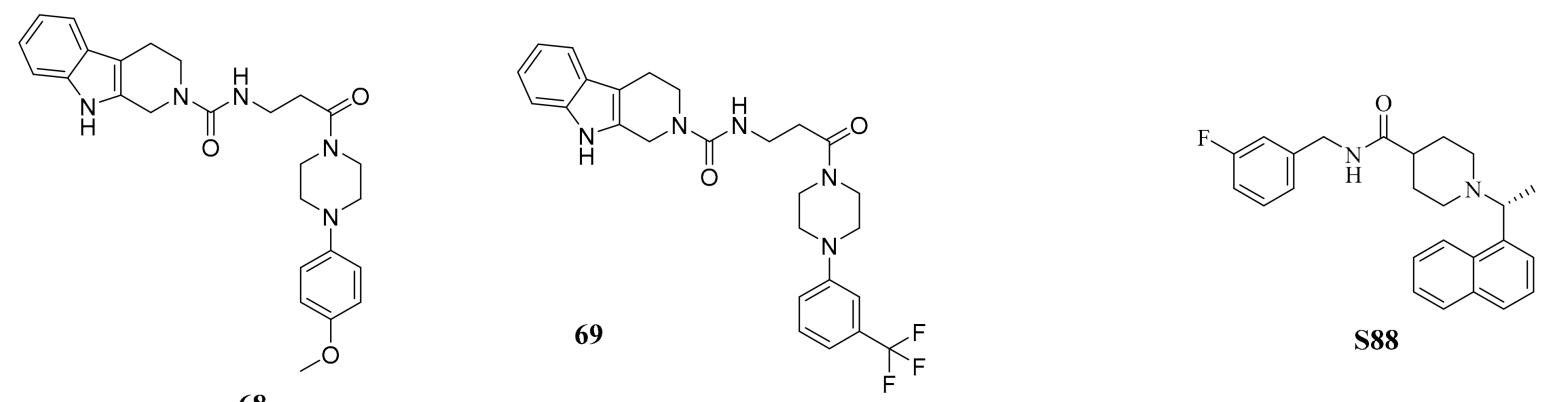

68

Figure 2. The chemical structures of the examined molecules. 


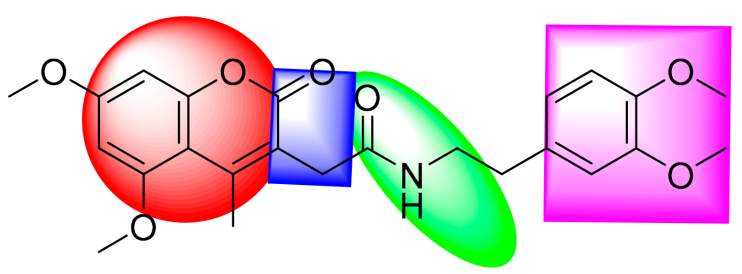

17

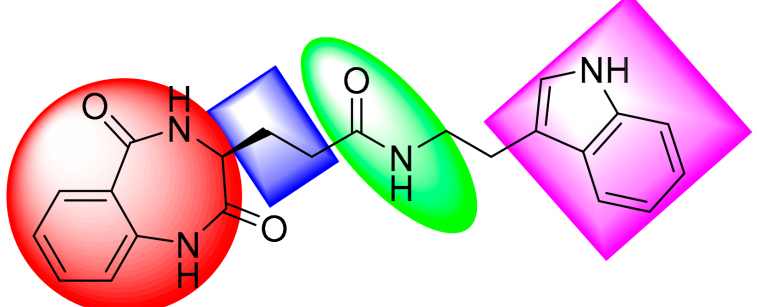

34

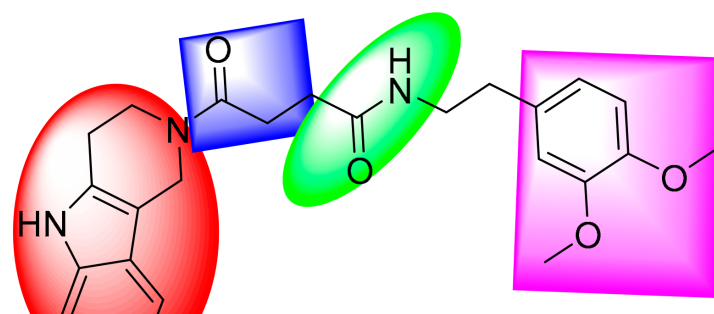

28

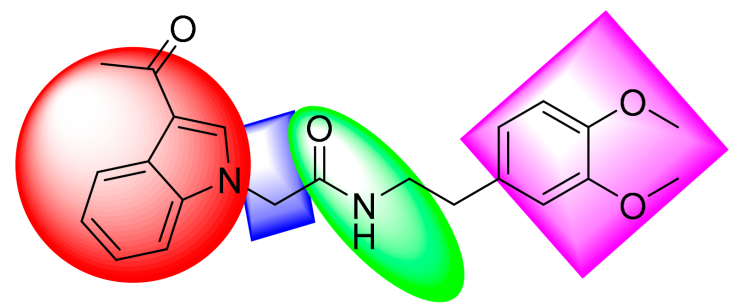

47

Figure 3. Representative sample of the examined semi-synthesized molecules having the main features of PLPIs.

\section{Results}

\subsection{Docking Studies}

MOE software was used to conduct docking studies (Supplementary Materials) on the investigated derivatives, with co-crystallized ligand S88 as a reference. The study aimed at getting a deeper insight into the binding modes of the examined semi-synthesized molecules in the active site of the coronavirus papain-like protease (PLpro) enzyme (PDB ID: (4OW0)). The docking method was validated through redocking of the co-crystallized ligand in the enzyme active site. The protocol's applicability was confirmed through the demonstration of small RMSD $(0.54 \AA)$ between the co-crystallized pose and the re-docked one (Figure 4).

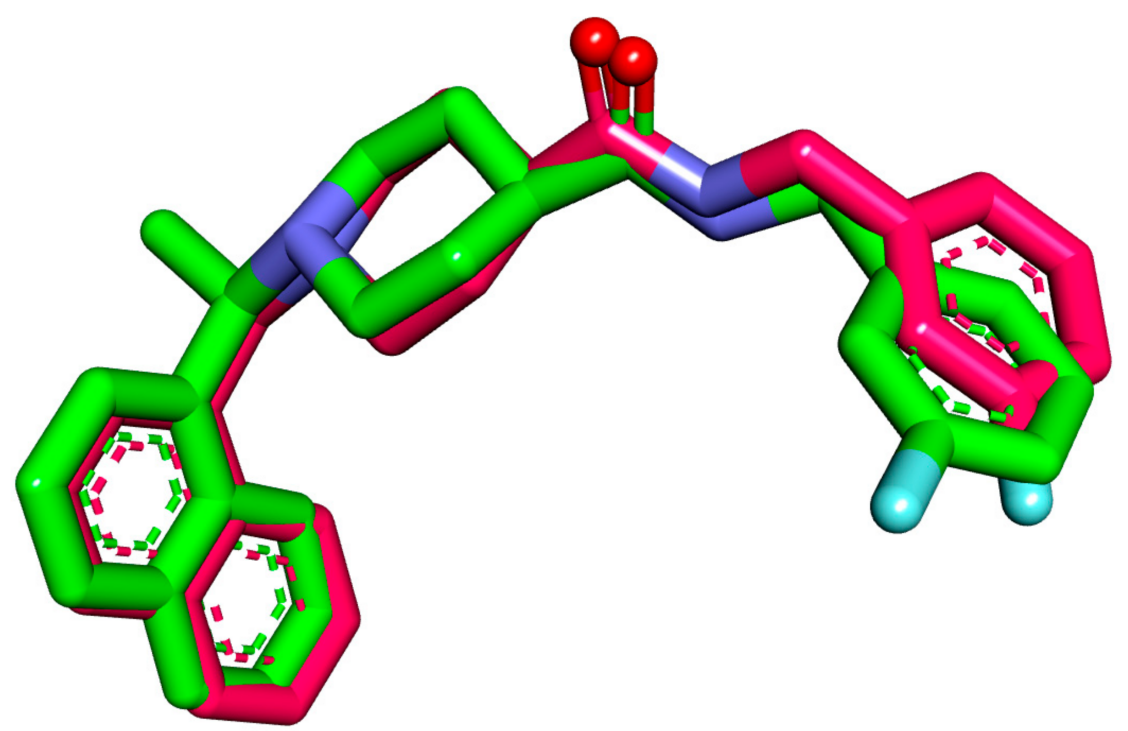

Figure 4. Superimposition of the redocked pose colored in pink against the co-crystallized one colored in green (S88) in PLpro active site. 
In this study, we relied on the corrected mode of binding of the examined semisynthesized molecules and S88 as well as the values of the binding free energy $(\Delta G)$ between them. Table 1 illustrates the calculated $\Delta \mathrm{G}$ of the tested semi-synthesized molecules and (S88) against the coronavirus papain-like protease enzyme. The semi-synthesized molecules 34 and 58 showed affinity values of -8.97 and -8.65 , respectively, that were higher than that of the redocked ligand $\mathbf{S 8 8}(-8.59 \mathrm{kcal} / \mathrm{mol})$. Moreover, the semisynthesized molecules 17, 28, 31, 40, 41, 43, 47, 54 and 65 revealed binding energy scores ranging from -8.33 to $-8.57 \mathrm{kcal} / \mathrm{mol}$, which were highly close to the redocked ligand S88. On the other hand, the other semi-synthesized molecules demonstrated affinity values lower than $\mathbf{S 8 8 .}$

Table 1. The calculated $\Delta \mathrm{G}$ in $\mathrm{Kcal} / \mathrm{mol}$ of the semi-synthesized molecules 1-69 and $\mathbf{S 8 8}$ against PLpro.

\begin{tabular}{|c|c|c|c|}
\hline Comp. & $\Delta \mathrm{G}$ & Comp. & $\Delta \mathrm{G}$ \\
\hline 1 & -7.55 & 36 & -7.49 \\
\hline 2 & -7.66 & 37 & -7.47 \\
\hline 3 & -8.07 & 38 & -8.04 \\
\hline 4 & -7.27 & 39 & -7.92 \\
\hline 5 & -7.54 & 40 & -8.54 \\
\hline 6 & -7.78 & 41 & -8.39 \\
\hline 7 & -6.72 & 42 & -8.22 \\
\hline 8 & -7.44 & 43 & -8.53 \\
\hline 9 & -8.06 & 44 & -7.79 \\
\hline 10 & -6.79 & 45 & -7.47 \\
\hline 11 & -7.42 & 46 & -7.67 \\
\hline 12 & -6.73 & 47 & -8.57 \\
\hline 13 & -7.57 & 48 & -7.22 \\
\hline 14 & -7.35 & 49 & -7.28 \\
\hline 15 & -7.54 & 50 & -8.13 \\
\hline 16 & -8.08 & 51 & -8.27 \\
\hline 17 & -8.50 & 52 & -7.59 \\
\hline 18 & -8.05 & 53 & -7.63 \\
\hline 19 & -7.34 & 54 & -8.33 \\
\hline 20 & -6.55 & 55 & -7.60 \\
\hline 21 & -7.08 & 56 & -7.10 \\
\hline 22 & -7.19 & 57 & -8.34 \\
\hline 23 & -5.80 & 58 & -8.65 \\
\hline 24 & -6.15 & 59 & -8.01 \\
\hline 25 & -7.98 & 60 & -8.22 \\
\hline 26 & -6.86 & 61 & -7.58 \\
\hline 27 & -6.05 & 62 & -7.98 \\
\hline 28 & -8.48 & 63 & -7.50 \\
\hline
\end{tabular}


Table 1. Cont.

\begin{tabular}{cccc}
\hline Comp. & $\Delta \mathrm{G}$ & Comp. & $\Delta \mathrm{G}$ \\
\hline 29 & -8.12 & 64 & -8.07 \\
\hline 30 & -7.48 & 65 & -8.33 \\
\hline 31 & -8.33 & 66 & -8.15 \\
\hline 32 & -8.11 & 67 & -7.86 \\
\hline 33 & -7.50 & 68 & -8.20 \\
\hline 34 & -8.97 & 69 & -8.18 \\
\hline 35 & -7.72 & ligandS88 & -8.59 \\
\hline
\end{tabular}

The proposed binding mode of the redocked ligand S88 revealed an affinity value of $-8.59 \mathrm{kcal} / \mathrm{mol}$. This high binding affinity is probably attributed to the formation of two hydrogen-bonding interactions. One was formed between the $\mathrm{N}-\mathrm{H}$ group of the amide moiety and Tyr269 while the other was formed between the nitrogen atom of the pyridine ring and Asp165. Additionally, the naphthyl moiety formed four hydrophobic interactions with Tyr269 and Pro249. These results were found to be consistent with the reported data [45] (Figure 5).

The docking simulation of compound 28 revealed that it has a good fitting into the enzyme active site with a docking score of $-8.48 \mathrm{kcal} / \mathrm{mol}$. The oxygen of the carbonyl group formed one hydrogen bond with the essential amino acid Tyr269. Additionally, the NH group of the pyrrole ring formed one hydrogen bond with Ala247. The 2,3,4,5tetrahydro-1 $H$-pyrido[4,3-b]indole moiety formed Tyr265, Asp165, and Pro248 (Figure 6).

As illustrated in Figure 7, compound 34 possessed a significant potential binding affinity $(\Delta \mathrm{G}=-8.97 \mathrm{kcal} / \mathrm{mol})$ into the papain-like protease active site. This high binding affinity, which is higher than ligand S88, presumably attributed to the formation of one hydrogen bond interaction with Arg167. In addition, the $1 H$-indole formed two hydrophobic interactions with Lys158 and Leu163.

Investigation of the top docking poses of compounds $\mathbf{4 7}$ and $\mathbf{5 4}$ (affinity values of -8.57 and $8.33 \mathrm{kcal} / \mathrm{mol}$ ) respectively, demonstrated that compound 47 formed one hydrogen bond interaction with Tyr269. In addition, it formed two hydrophobic interactions with Pro249 and Lys158. Compound 54 formed two hydrogen bonds with the essential amino acid Tyr269 and Tyr265. In addition, it formed two hydrophobic interactions with Lys158 and Arg167 in the active site of PLpro. Figures 8 and 9.

The binding mode of compound 58 (affinity value of $-8.65 \mathrm{kcal} / \mathrm{mol}$ ) was better than ligand S88. In detail, the amide moiety formed one hydrogen bond with fundamental amino acid Asp165, and NH of the pyrrole ring formed another hydrogen bond with Glu168. Furthermore, it formed aromatic stacking interactions (4 pi-cation bonds) with Tyr269, Tyr265, and Arg167 (Figure 10).

\subsection{Pharmacokinetic Profiling Study}

An in silico computational evaluation of the physicochemical properties and profiling pharmacokinetics for the most active eleven semi-synthesized molecules, with ligand S88 as a reference compound, were conducted. The oral absorption of a drug is more likely to be better if the molecule fulfills at least three of the four principles of the Lipinski rules, listed below: (1) $\mathrm{H}$ bond donors $(\mathrm{OH}, \mathrm{NH}$, and $\mathrm{SH}) \leq 5$; (2) $\mathrm{H}$ bond acceptors $(\mathrm{N}, \mathrm{O}$, and $\mathrm{S}$ atoms) $\leq 10$; (3) molecular weight $<500$; (4) $\log \mathrm{P}<5$. The bioavailability of compounds that violate more than one of these requirements is unlikely to be high. Moreover, reduced molecular flexibility, as measured by the number of rotatable bonds, and low polar surface area are found to be important predictors of good oral bioavailability [50]. Compounds with 10 or fewer rotatable bonds and a polar surface area of $140 \AA$ or less have a high probability of good oral bioavailability [50,51]. 


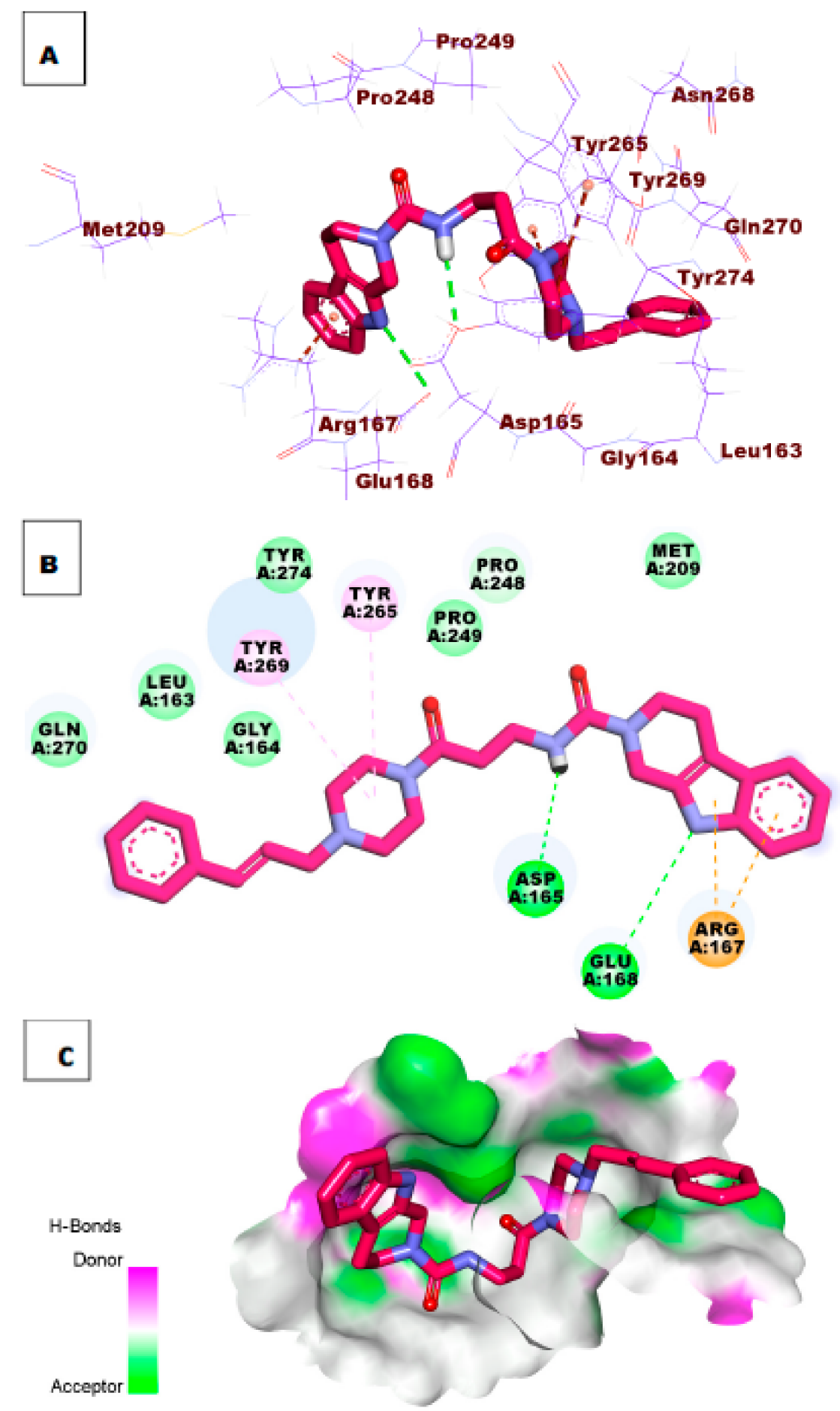

Figure 5. (A) 3D of S88 docked into the active site of PLpro. (B) 2D of S88 docked into the active site of PLpro. (C) Surface mapping of $\mathbf{S 8 8}$ docked into the active site of PLpro. 


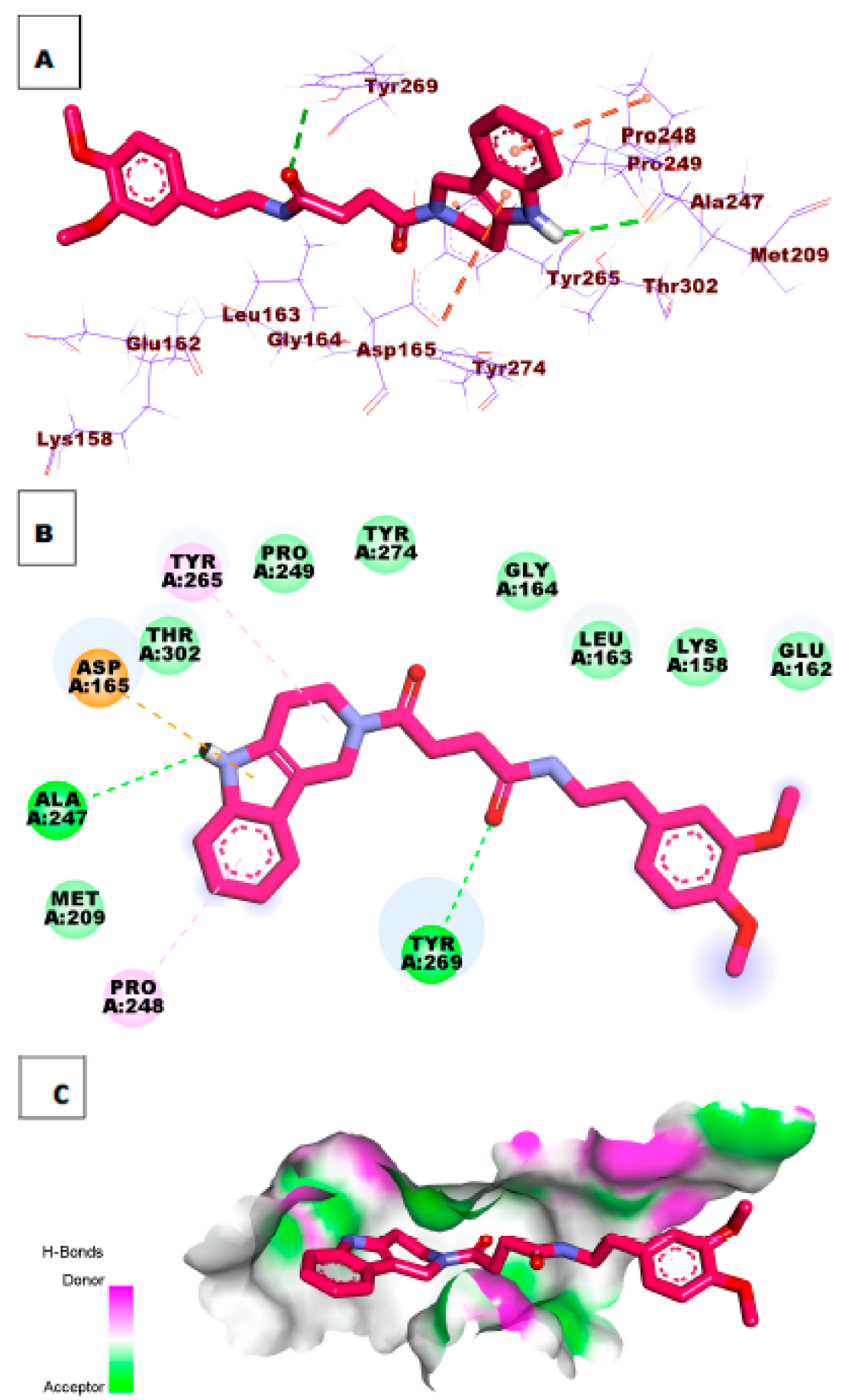

Figure 6. (A) 3D of compound 28 docked into the active site of PLpro. (B) 2D of compound 28 docked into the active site of PLpro. (C) Surface mapping of compound 28 docked into the active site of PLpro. 


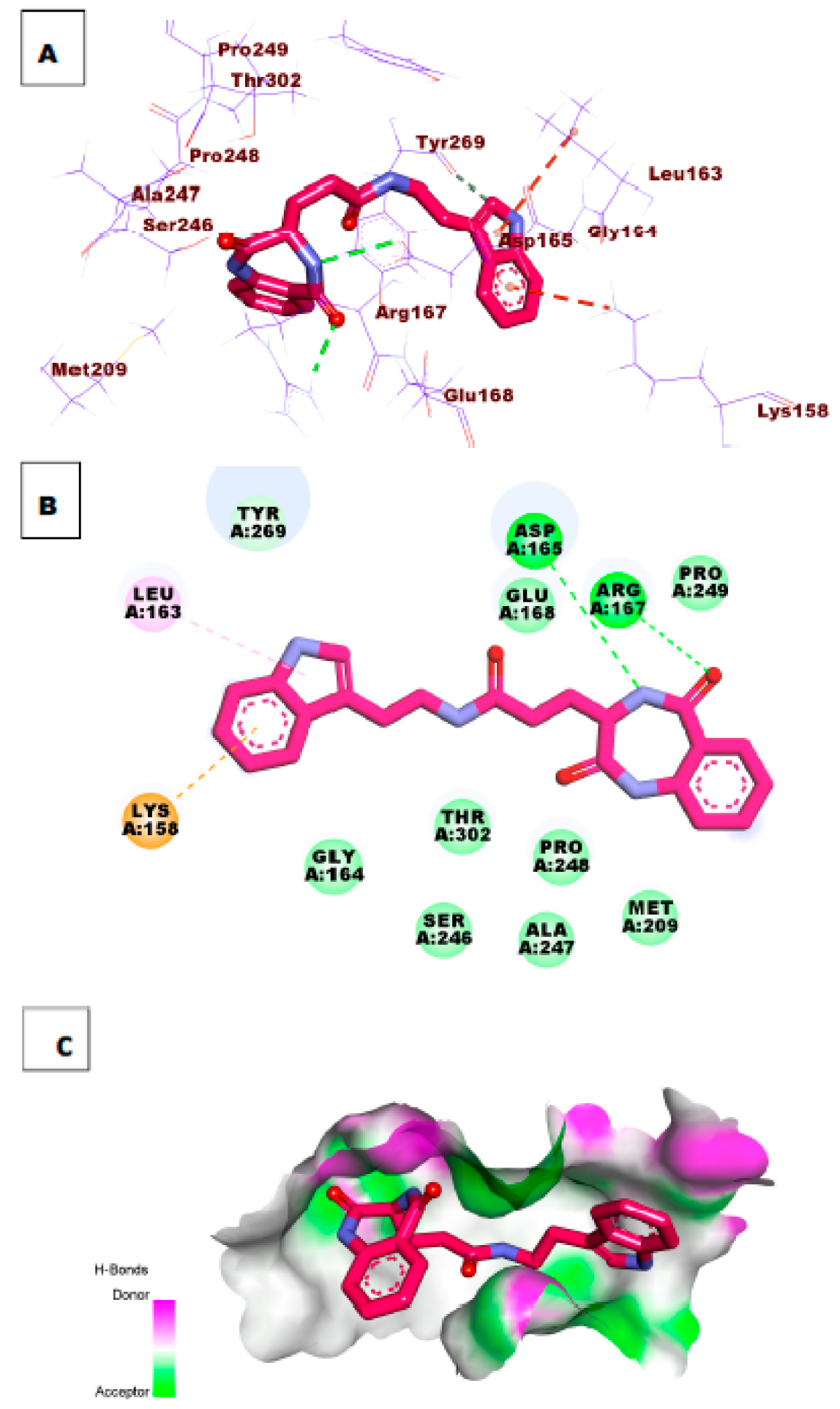

Figure 7. (A) 3D of compound 34 docked into the active site of PLpro. (B) 2D of compound 34 docked into the active site of PLpro. (C) Surface mapping of compound 34 docked into the active site of PLpro. 

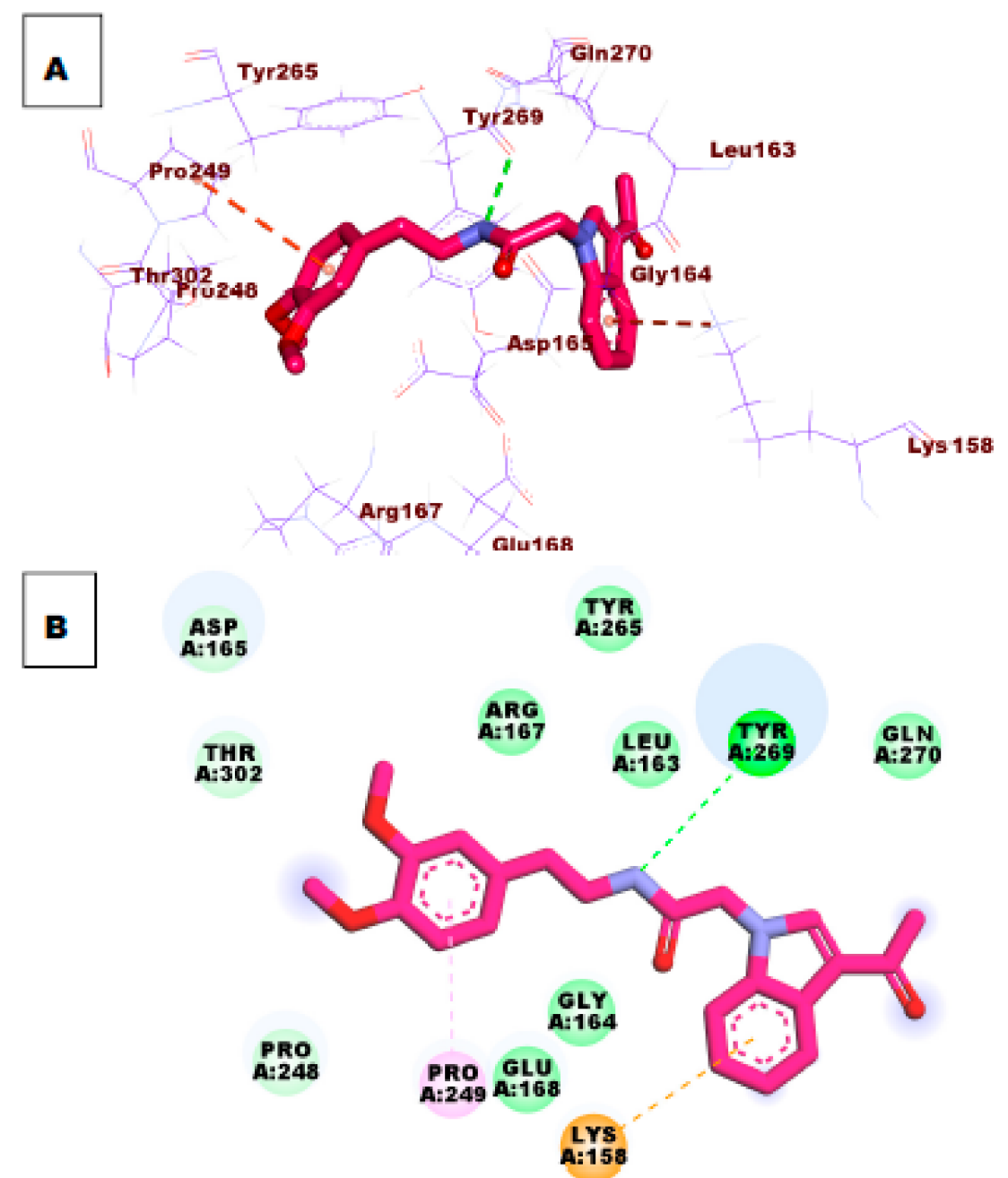

c

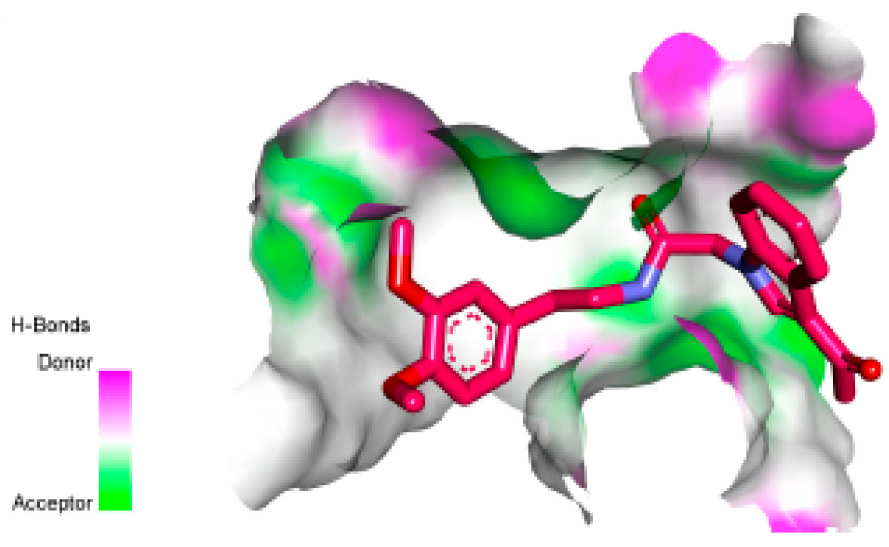

Figure 8. (A) 3D of compound 47 docked into the active site of PLpro. (B) 2D of compound 47 docked into the active site of PLpro. (C) Surface mapping of compound 47 docked into the active site of PLpro. 


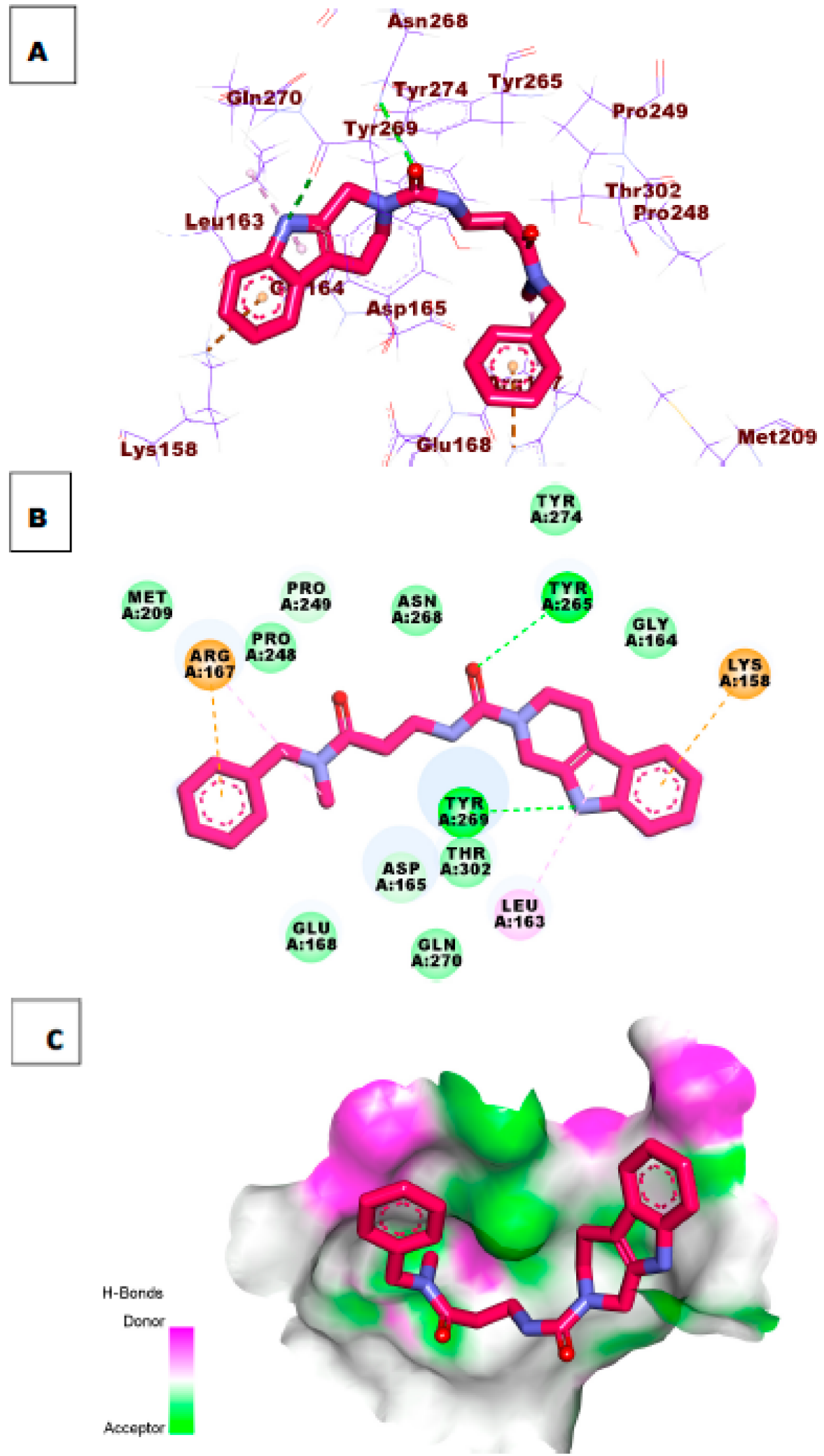

Figure 9. (A) 3D of compound 54 docked into the active site of PLpro. (B) 2D of compound 54 docked into the active site of PLpro. (C) Surface mapping of compound 54 docked into the active site of PLpro. 


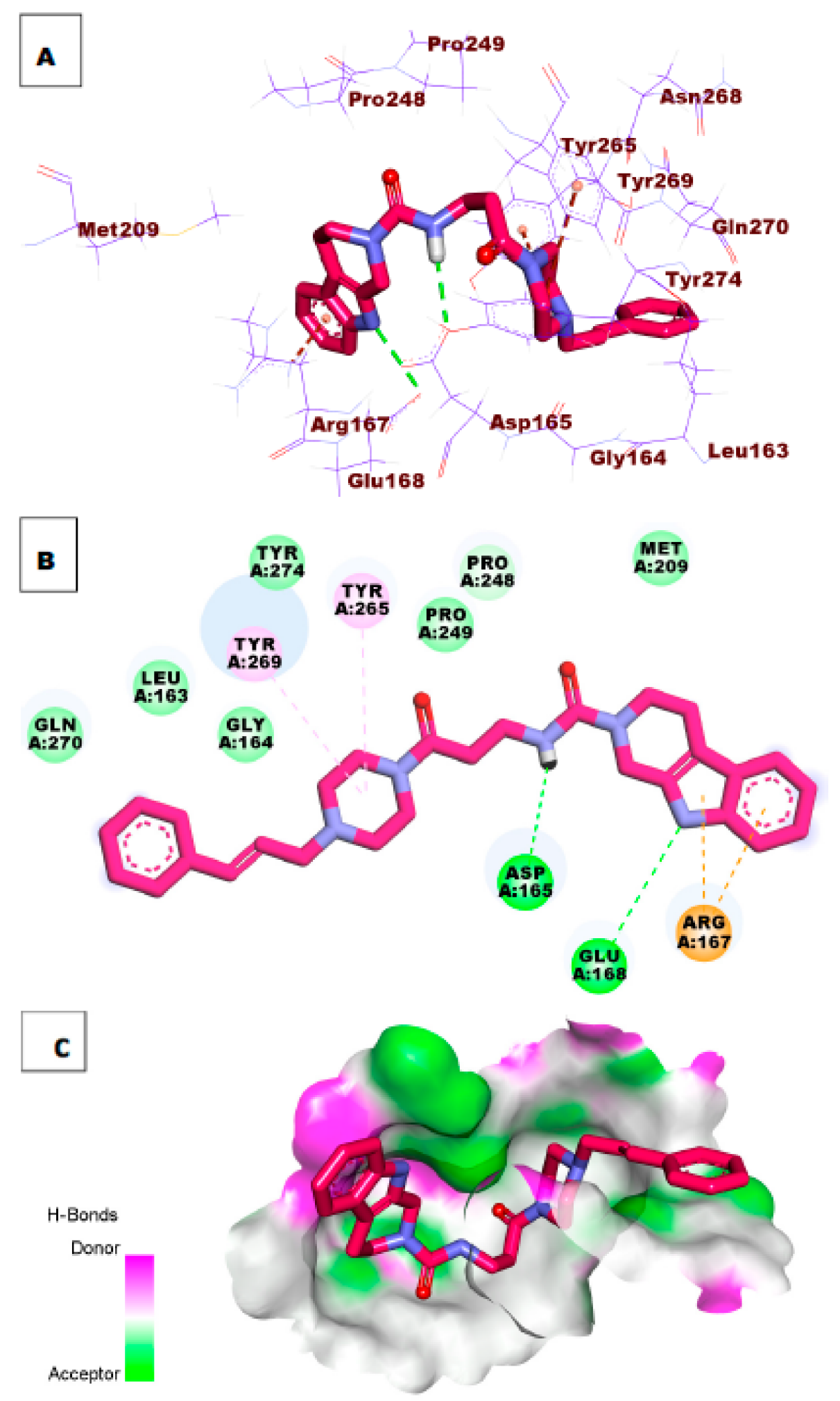

Figure 10. (A) 3D of compound 58 docked into the active site of PLpro. (B) 2D of compound 58 docked into the active site of PLpro. (C) Surface mapping of compound 58 docked into the active site of PLpro.

The results, given in Table 2, revealed that all tested semi-synthesized molecules and reference ligand S88 showed no violation of Lipinski's rule except compound 31 (the Log P of compounds $\mathbf{3 1}$ was anticipated to be more than 5). 
Table 2. Physicochemical properties of the semi-synthesized molecules under study.

\begin{tabular}{|c|c|c|c|c|c|c|c|}
\hline \multirow[b]{2}{*}{ Compound } & \multicolumn{5}{|c|}{ Lipinski's Rule of 5} & \multicolumn{2}{|c|}{ Veber's Rule } \\
\hline & $\log P$ & Mole. Wt. & HBD & HBA & $\begin{array}{c}\text { Violation } \\
\text { of Lipinski's Rule }\end{array}$ & $\begin{array}{c}\text { Number of Rotatable } \\
\text { Bonds }\end{array}$ & TPSA \\
\hline 17 & 3.38 & 441.47 & 1 & 7 & 0 & 9 & 92.32 \\
\hline 28 & 2.83 & 435.51 & 2 & 4 & 0 & 8 & 83.66 \\
\hline 31 & 5.69 & 485.5 & 2 & 4 & 1 & 7 & 88.77 \\
\hline 34 & 1.8 & 390.43 & 4 & 3 & 0 & 6 & 103.09 \\
\hline 40 & 1.46 & 389.46 & 1 & 5 & 0 & 7 & 109 \\
\hline 41 & 1.96 & 426.46 & 1 & 6 & 0 & 7 & 86.33 \\
\hline 43 & 1.73 & 449.5 & 1 & 6 & 0 & 9 & 98.58 \\
\hline 47 & 3 & 380.43 & 1 & 4 & 0 & 8 & 69.56 \\
\hline 54 & 2.7 & 390.47 & 2 & 2 & 0 & 5 & 68.44 \\
\hline 58 & 1.56 & 472.6 & 3 & 2 & 0 & 6 & 72.88 \\
\hline 65 & 3.41 & 465.97 & 2 & 3 & 0 & 4 & 71.68 \\
\hline S88 & 3.09 & 391.5 & 2 & 1 & 0 & 5 & 33.54 \\
\hline
\end{tabular}

\subsection{ADMET Studies}

S88 and favipiravir were used as reference drugs in ADMET studies for the most active eleven semi-synthesized molecules using Discovery studio 4.0 software. ADMET studies include many descriptors. The predicted descriptors are listed in Table 3. All tested semi-synthesized molecules and favipiravir showed BBB penetration levels ranging from medium to low except compound 31, which displayed a very low BBB penetration level, and ligand S88 showed a high BBB penetration level. All semi-synthesized molecules, favipiravir, and ligand S88 have good absorption behavior except compound 31, which is expected to have a moderate absorption level. Moreover, the solubility level of the semi-synthesized molecules is projected to be better than or even comparable to that of the S88, which showed a low solubility level, except compound $\mathbf{3 1}$ that showed a very low solubility level. On the other hand, favipiravir demonstrated an optimal solubility level. All examined semi-synthesized molecules and favipiravir were predicted to be noninhibitors of CYP2D6 except compounds 31, 34, 47, and S88. Hepatotoxicity predictions found that all of the tested compounds and ligand $\mathbf{S 8 8}$ are predicted to be non-toxic except compounds 17, 31, 41, 43 and favipiravir, which have unfavorable hepatotoxic effects. All tested semi-synthesized molecules and $\mathbf{S 8 8}$ were expected to bind to plasma proteins more than $90 \%$ except compounds 28, 40, 43, 54, and favipiravir (Figure 11).

Table 3. Predicted ADMET descriptors for the examined compounds, S88, and favipiravir.

\begin{tabular}{|c|c|c|c|c|c|c|}
\hline Comp. No. & BBB Level ${ }^{1}$ & $\begin{array}{l}\text { Absorption } \\
\text { Level }^{2}\end{array}$ & $\begin{array}{l}\text { Solubility } \\
\text { Level }^{3}\end{array}$ & CYP2D6 ${ }^{4}$ & $\begin{array}{l}\text { Hepatotoxicity } \\
\text { Probability }\end{array}$ & PPB $^{6}$ \\
\hline 17 & ++ & +++ & ++ & - ve & 0.549 & 2 \\
\hline 28 & ++ & +++ & +++ & - ve & 0.37 & 0 \\
\hline 31 & + & ++ & + & $+\mathrm{ve}$ & 0.629 & 2 \\
\hline 34 & ++ & +++ & +++ & + ve & 0.47 & 1 \\
\hline 40 & ++ & +++ & +++ & -ve & 0.437 & 0 \\
\hline 41 & ++ & +++ & +++ & - ve & 0.821 & 2 \\
\hline 43 & ++ & +++ & +++ & - ve & 0.622 & 0 \\
\hline 47 & +++ & +++ & ++ & + ve & 0.456 & 2 \\
\hline 54 & +++ & +++ & +++ & - ve & 0.092 & 0 \\
\hline 58 & ++ & +++ & +++ & - ve & 0.324 & 2 \\
\hline 65 & +++ & +++ & ++ & - ve & 0.271 & 2 \\
\hline S88 & ++++ & +++ & ++ & +ve & 0.092 & 1 \\
\hline Favipiravir & ++ & +++ & ++++ & - ve & 0.728 & 0 \\
\hline
\end{tabular}

${ }^{1}$ BBB level: $++++=$ high,$+++=$ medium,$++=$ low, $+=$ very low. ${ }^{2}$ Absorption level: $+++=$ good,$++=$ moderate, $+=$ poor. ${ }^{3}$ solubility level: $+=$ very low,$++=$ low,$+++=$ good,$++++=$ optimal. ${ }^{4}$ CYP2D6 (cytochrome P2D6); - ve = non inhibitor, + ve $=$ inhibitor. ${ }^{5}$ Hepatotoxicity probability: value $>0.5$ means toxic, value $<0.5$ means non-toxic. ${ }^{6} \mathrm{PPB}$ (plasma protein binding): 0 means less than $90 \%, 1$ means more than $90 \%, 2$ means more than $95 \%$. 


\subsection{Toxicity Studies}

Discovery Studio 4.0 software was used to generate toxicity predictions for the most active eleven semi-synthesized molecules, which were based on validated and assembled models as follows: FDA rat carcinogenicity [52,53], carcinogenic potency $\mathrm{TD}_{50}$ [54], rat maximum tolerated dose (MTD) [55,56], rat oral $\mathrm{LD}_{50}$ [57], rat chronic LOAEL [58,59], ocular irritancy [60] and skin [19,60,61].

As shown in Table 4, most of the examined semi-synthesized molecules have low toxicity. All the tested semi-synthesized molecules are non-carcinogens except 54, 58, and S88, which were predicted to be carcinogens. All tested semi-synthesized molecules showed $\mathrm{TD}_{50}$ values ranging from 0.31 to $1.86 \mathrm{mg} / \mathrm{kg}$ body weight/day, which were lower than S88 ( $2.54 \mathrm{mg} / \mathrm{kg}$ body weight/day), except compounds 17, 31, 40, and 47 that showed $\mathrm{TD}_{50}$ values of 5.57, 5.32, 10.31 and $14.54 \mathrm{mg} / \mathrm{kg}$ body weight/day, respectively, which were higher than S88. All the investigated semi-synthesized molecules revealed a maximum tolerated dose with a range of 0.045 to $0.122 \mathrm{~g} / \mathrm{kg}$ body weight that was lower than S88 (0.124 g/ kg body weight) except compounds 16, 28, 31, and 34, which demonstrated maximum tolerated doses of $0.142,0.144,0.369$ and $0.328 \mathrm{~g} / \mathrm{kg}$ body weight, respectively, which were higher than S88. All tested semi-synthesized molecules showed oral $\mathrm{LD}_{50}$ values ranging from 2.97 to $32.39 \mathrm{mg} / \mathrm{kg}$ body weight/day that were higher than the $\mathrm{LD}_{50}$ value of $\mathbf{S 8 8}(1.229 \mathrm{mg} / \mathrm{kg}$ body weight/day), except compound 31, which revealed an oral $\mathrm{LD}_{50}$ value of $0.251 \mathrm{mg} / \mathrm{kg}$ body weight/day, which was lower than S88. Semi-synthesized molecules 54, 58, and 65 showed LOAEL values of $0.015,0.001$, and $0.018 \mathrm{~g} / \mathrm{kg}$ body weight, respectively. These values were lower than $\mathbf{S 8 8}(0.035 \mathrm{~g} / \mathrm{kg}$ body weight), while other semi-synthesized molecules revealed rat chronic LOAEL values ranging from 0.039 to $0.539 \mathrm{~g} / \mathrm{kg}$ body weight, which were higher than S88. Moreover, all the tested semi-synthesized molecules and $\mathbf{S 8 8}$ were predicted to be mild irritants against the ocular irritancy model. On the other hand, the examined semi-synthesized molecules and S88 were expected to be non-irritant against the skin irritancy model except compound 58, which was anticipated to be a mild skin irritant.

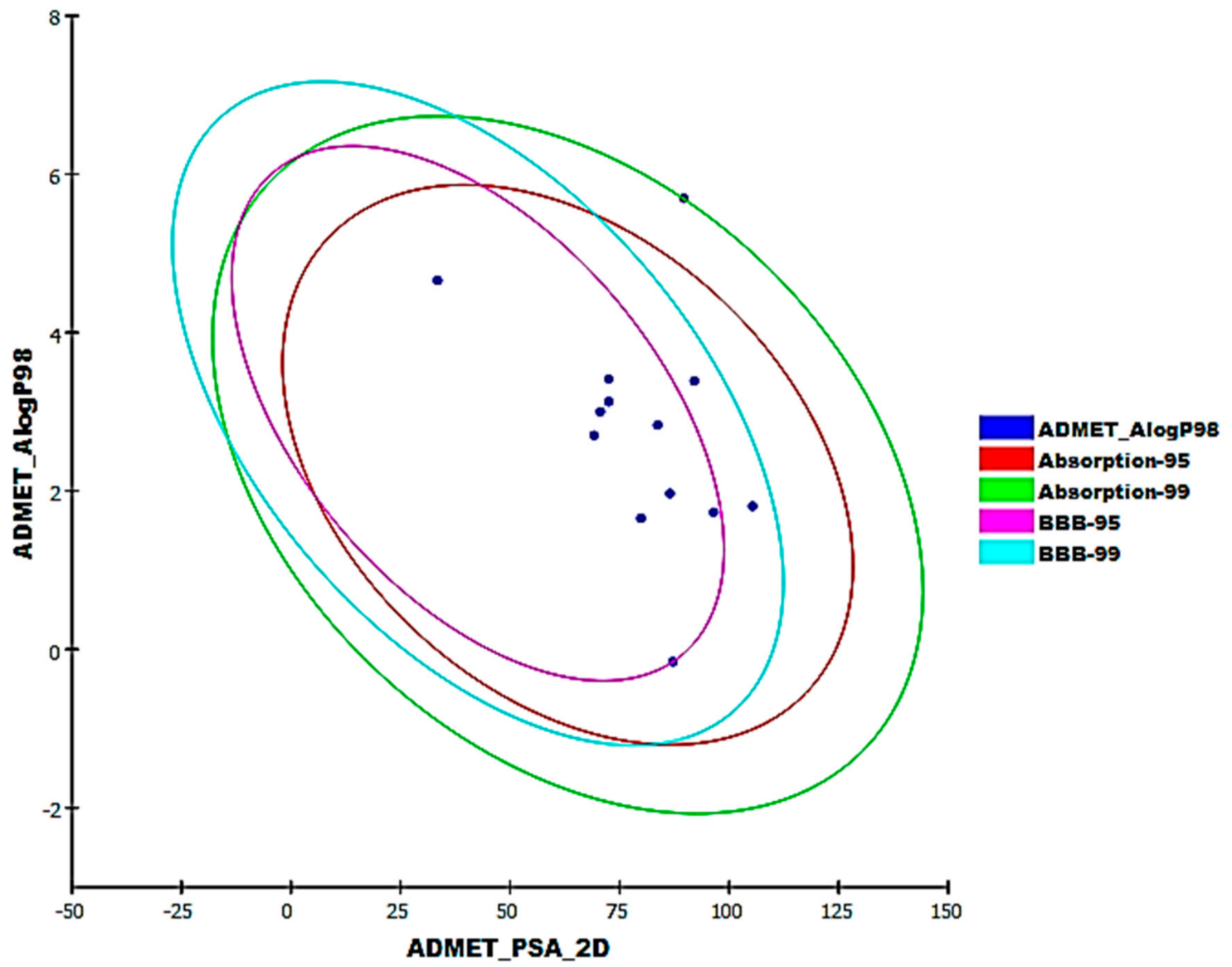

Figure 11. The expected ADMET study of the most potent semi-synthesized molecules. 
Table 4. Toxicity properties of tested compounds and S88.

\begin{tabular}{|c|c|c|c|c|c|c|c|}
\hline Comp. & $\begin{array}{l}\text { FDA Rat } \\
\text { Carcinogenicity }\end{array}$ & $\begin{array}{l}\text { Carcinogenic } \\
\text { Potency TD } \\
\text { (Rat) }^{2}\end{array}$ & $\begin{array}{l}\text { Rat Maximum } \\
\text { Tolerated Dose } \\
\quad\left(\text { Feed) }{ }^{3}\right.\end{array}$ & $\begin{array}{c}\text { Rat Oral } \\
\operatorname{LD}_{50}\end{array}$ & $\begin{array}{c}\text { Rat } \\
\text { Chronic } \\
\text { LOAEL }^{3}\end{array}$ & $\begin{array}{l}\text { Ocular } \\
\text { Irritancy }\end{array}$ & $\begin{array}{c}\text { Skin } \\
\text { Irritancy }\end{array}$ \\
\hline 17 & $-\mathrm{ve}$ & 5.577 & 0.142 & 4.097 & 0.039 & Mild & None \\
\hline 28 & - ve & 1.199 & 0.144 & 27.190 & 0.539 & Mild & None \\
\hline 31 & $-\mathrm{ve}$ & 5.323 & 0.369 & 0.251 & 0.043 & Mild & None \\
\hline 34 & - ve & 0.826 & 0.328 & 32.393 & 0.232 & Mild & None \\
\hline 40 & $-\mathrm{ve}$ & 10.310 & 0.033 & 14.820 & 0.339 & Mild & None \\
\hline 41 & $-\mathrm{ve}$ & 1.162 & 0.122 & 26.756 & 0.446 & Mild & None \\
\hline 43 & - ve & 1.860 & 0.100 & 26.741 & 0.151 & Mild & None \\
\hline
\end{tabular}

Table 4. Cont.

\begin{tabular}{|c|c|c|c|c|c|c|c|}
\hline Comp. & $\begin{array}{l}\text { FDA Rat } \\
\text { Carcinogenicity }^{1}\end{array}$ & $\begin{array}{l}\text { Carcinogenic } \\
\text { Potency TD } \\
\text { (Rat) }^{2}\end{array}$ & $\begin{array}{l}\text { Rat Maximum } \\
\text { Tolerated Dose } \\
\quad \text { (Feed) }\end{array}$ & $\underset{\mathrm{LD}_{50}{ }_{3}}{\text { Rat Oral }}$ & $\begin{array}{c}\text { Rat } \\
\text { Chronic } \\
\text { LOAEL }^{3}\end{array}$ & $\underset{\text { Irritancy }}{\text { Ocular }}$ & $\begin{array}{l}\text { Skin } \\
\text { Irritancy }\end{array}$ \\
\hline 47 & -ve & 14.544 & 0.045 & 8.150 & 0.139 & Mild & None \\
\hline 54 & +ve & 0.324 & 0.068 & 5.277 & 0.015 & Mild & None \\
\hline 58 & +ve & 1.725 & 0.071 & 5.145 & 0.001 & Mild & Mild \\
\hline 65 & - ve & 0.315 & 0.117 & 2.971 & 0.018 & Mild & None \\
\hline S88 & $+\mathrm{ve}$ & 2.548 & 0.124 & 1.229 & 0.035 & Mild & None \\
\hline
\end{tabular}

\subsection{DFT Studies}

DFT parameters, including total energy [62], HOMO [63], LUMO [63], gap energy [64], and dipole moment $[65,66]$, were studied for the most semi-synthesized molecules 28, 34, and 47 using Discovery studio 4.0 software. The co-crystallized S88 was used as a reference molecule.

\subsubsection{Molecular Orbital Analysis}

The total energies of $\mathbf{2 8 , 3 4}, \mathbf{4 7}$, and S88 were $-1422.912,-1285.184,-1252.334$, and $1242.947 \mathrm{kcal} / \mathrm{mol}$, respectively. These results indicated that compound 28 has higher total energy than 34 and 47 and is expected to have a more efficient interaction with PLpro. Accordingly, compound 28 can bind more efficiently with PLpro than 34 and 47. Furthermore, the dipole moment values of $\mathbf{2 8 , 3 4}, \mathbf{4 7}$, and $\mathbf{S 8 8}$ were $2.790,1.558,2.249$, and 3.542 , respectively (Table 5). These values indicate that 28 has a higher dipole moment than compounds 34 and 47. Based on these findings, it was expected that compound 28 can easily form hydrogen bonds and non-bonded interactions with PLpro, which, consequently, leads to an increased binding affinity with the target receptor during SARS-CoV-2 inhibition. Therefore, compound $\mathbf{2 8}$ is considered the most promising candidate to interact with the target receptor.

Table 5. Spatial distribution of molecular orbitals for candidates 28, 34, 47 and S88.

\begin{tabular}{ccccccc}
\hline Name & $\begin{array}{c}\text { Total Energy } \\
\mathbf{( k c a l / m o l )}\end{array}$ & $\begin{array}{c}\text { Binding Energy } \\
\mathbf{( k c a l / m o l )}\end{array}$ & $\begin{array}{c}\text { HOMO Energy } \\
\mathbf{( k c a l / m o l )}\end{array}$ & $\begin{array}{c}\text { LUMO Energy } \\
\text { (kcal/mol) }\end{array}$ & $\begin{array}{c}\text { Dipole } \\
\text { Mag }\end{array}$ & $\begin{array}{c}\text { Band Gap Energy } \\
\mathbf{( k c a l / m o l )}\end{array}$ \\
\hline $\mathbf{2 8}$ & -1422.912 & -12.075 & -0.170 & -0.036 & 2.790 & 0.134 \\
$\mathbf{3 4}$ & -1285.184 & -10.458 & -0.175 & -0.076 & 1.558 & 0.099 \\
$\mathbf{4 7}$ & -1252.334 & -10.395 & -0.172 & -0.075 & 2.249 & 0.097 \\
S88 & -1242.947 & -11.176 & -0.292 & -0.187 & 3.542 & 0.105 \\
\hline
\end{tabular}

As reported, HOMO and LUMO have a key role in chemical stability and reactivity [67]. Compound 28 had a gap energy value of $0.134 \mathrm{kcal} / \mathrm{mol}$, which is higher than that 
of compounds $34(0.099 \mathrm{kcal} / \mathrm{mol})$ and $47(0.097 \mathrm{kcal} / \mathrm{mol})$. The increased gap energy of compound 28 indicates the higher stability of this compound. Figure 12 showed the spatial distribution of molecular orbitals for the tested compounds.

\subsubsection{Molecular Electrostatic Potential Maps (MEP)}

MEP demonstrates the total electrostatic potential of a molecule in three dimensions depending on its partial charges, electronegativity, and chemical reactivity [68]. Identifying the electrostatic potential will help in the understanding of the drug's binding mode against a PLpro [69].

MEP displays the electronegative atoms (negative values) in red. Electronegative atoms act as hydrogen bonding acceptors. On the other hand, it displays electron-poor atoms (positive value) in blue. Electron-poor atoms act as hydrogen bonding donors. It displays the neutral atoms (zero values) in a green to yellow color. Neutral atoms can form $\pi$ - and other types of hydrophobic interactions. Such information facilitates the prediction of the chemical reaction and the binding mode with the biological target [70].

HOMO

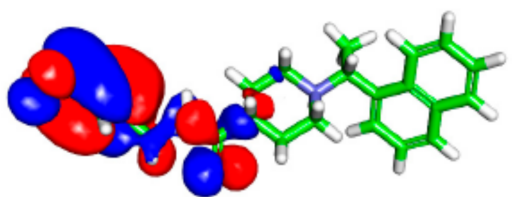

A

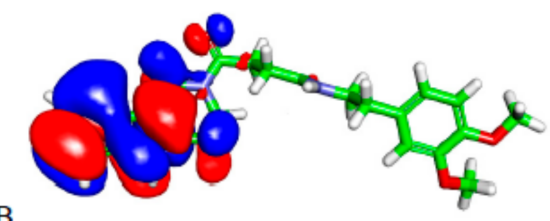

B

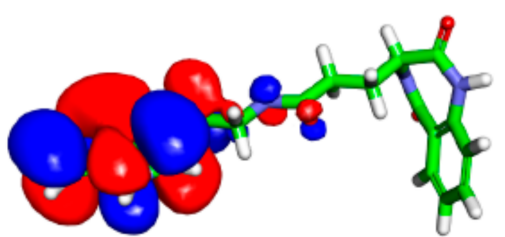

$\mathrm{C}$

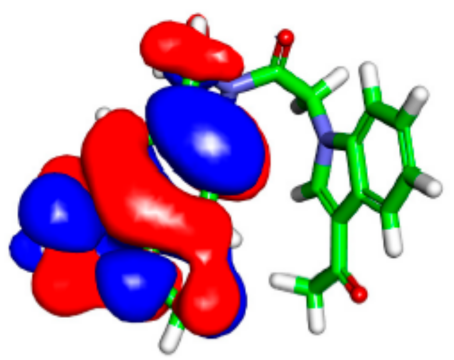

LUMO
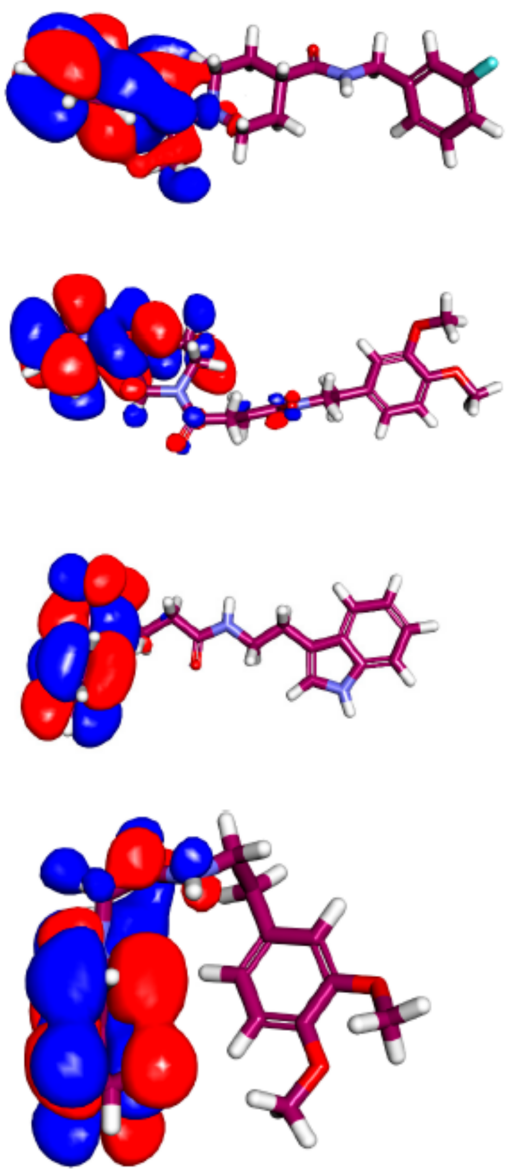

$\mathrm{D}$

Figure 12. Spatial distribution of molecular orbitals for (A) S88, (B) 28, and (C) 34, and (D) 47.

Compound 28 showed five red patches and two blue patches, which can form hydrogen bond acceptors and hydrogen bond donors, respectively. The aromatic moieties showed yellow patches, which can form hydrophobic interactions with hydrophobic amino acid residues (Figures 12 and 13).

Compounds 34 and $\mathbf{4 7}$ showed four red patches, which can form hydrogen bond acceptors. Compound 34 showed three red patches and two blue patches. The aromatic moieties 
of these compounds showed yellow patches which can form hydrophobic interactions with hydrophobic amino acid residues (Figures 12 and 13).

As compound 28 showed five red patches, this explains its high binding energy $(-8.48 \mathrm{kcal} / \mathrm{mol})$ and ability to form two hydrogen bonds in the docking procedure. The yellow patches on aromatic moieties facilitated the hydrophobic interaction with the target receptor. Compounds 34 and 47 showed four red patches in MEP, which clarified the formation of two and three hydrogen bonds, respectively. In addition, these compounds showed high binding energies of -8.97 and $-8.57 \mathrm{kcal} / \mathrm{mol}$, respectively.

A

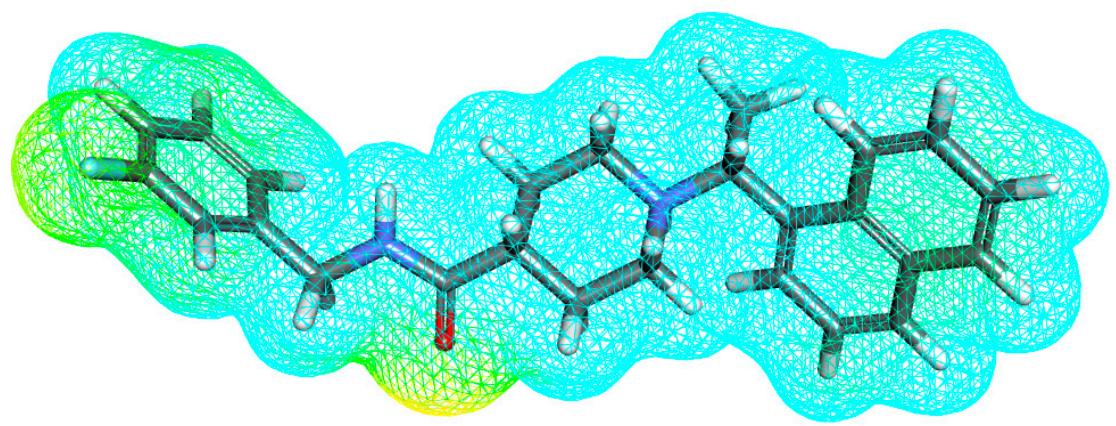

B

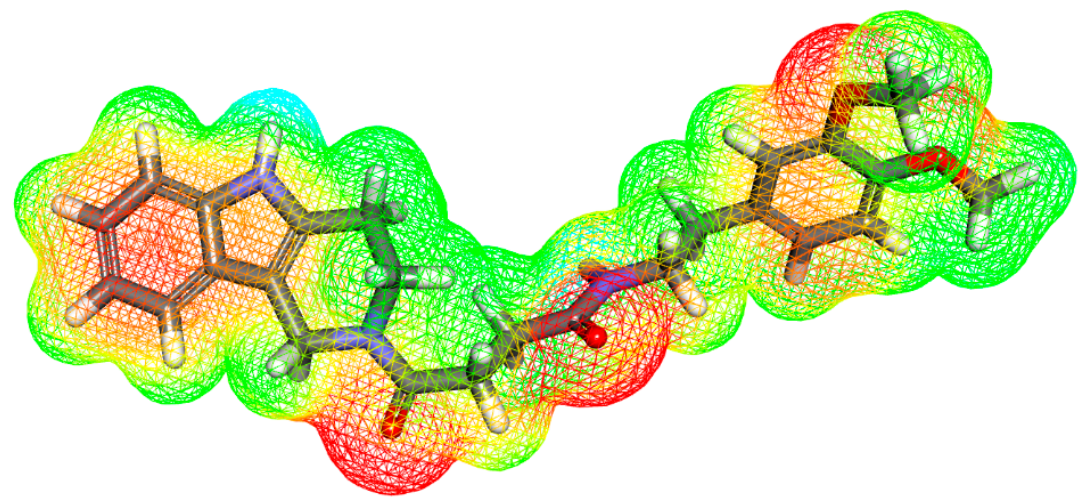

C

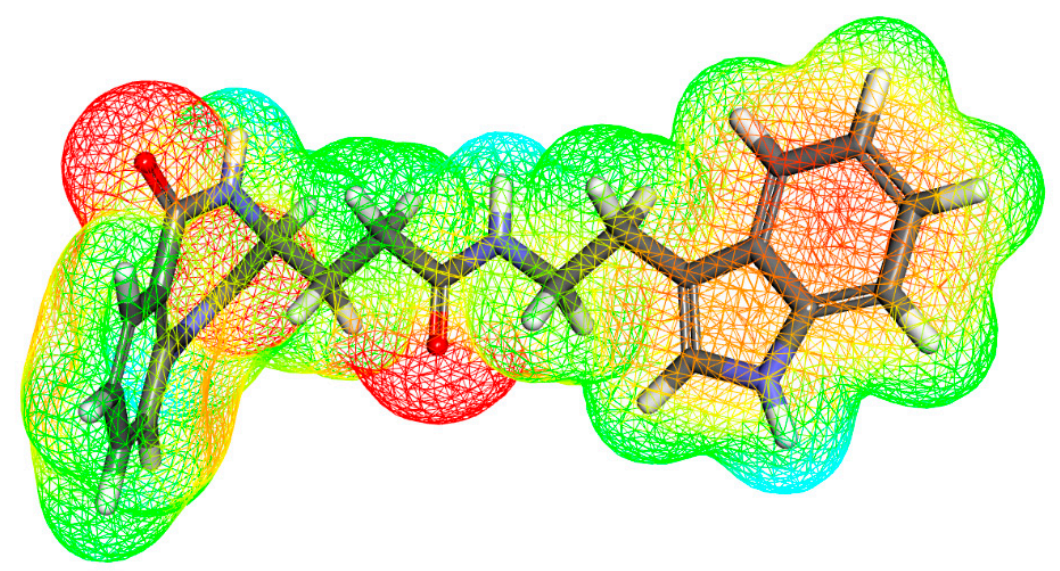

Figure 13. Cont. 


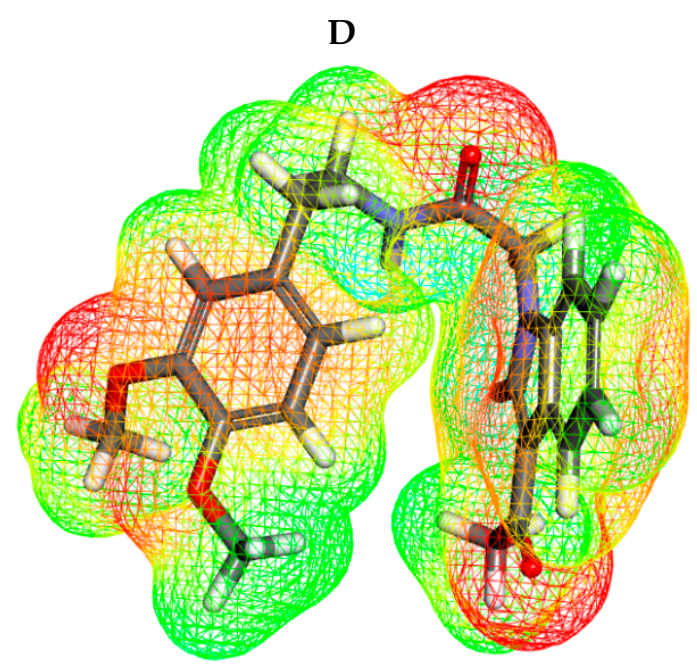

Figure 13. Molecular electrostatic potential map of (A) S88, (B) 28, and (C) 34, and (D) 47.

\section{Conclusions}

A set of 69 semi-synthesized molecules that exhibited the structural features of PLpro inhibitors (PLPI) were screened in silico to select the most potent inhibitor of PLpro enzyme (PDB ID: (4OW0). Docking studies showed that 11 molecules exhibited good binding modes and binding free energies. The pharmacokinetic profiling study excluded an unsuitable compound. Furthermore, ADMET and toxicity studies favored three molecules. Finally, a DFT study has been carried out and indicated that $\mathrm{N}$-(3,4-dimethoxyphenethyl)-4-oxo4-(1,3,4,5-tetrahydro-2H-pyrido[4,3-b]indol-2-yl)butanamide (28) is the most promising PLpro inhibitor. Further work has to be conducted to build on the presented results in the hopes of finding a cure.

\section{Method}

\subsection{Docking Studies}

Crystal structure of human coronavirus papain-like protease inhibitor [PDB ID: 4OW0, resolution: $2.10 \AA$ ] was obtained from Protein Data Bank. The docking investigation was accomplished using MOE2014 software. At first, the crystal structure of SARS-CoV-2 helicase was prepared by removing water molecules. Only one chain was retained beside the co-crystallized ligand (S88). Then, the selected chain was protonated and subjected to minimization of energy process. Next, the active site of the target protein was defined.

Structures of the tested compounds and the co-crystallized ligand were drawn using ChemBioDraw Ultra 14.0 and saved as MDL-SD format. Such file was opened using MOE to display the 3D structures which were protonated and subjected to energy minimization. Formerly, validation of the docking process was performed by docking the co-crystallized ligand against the isolated pocket of active site. The produced RMSD value indicated the validity of process. Finally, docking of the tested compounds was done through the dock option inserted in computer window. For each docked molecule, 30 docked poses were produced using ASE for scoring function and force field for refinement. The retain was kept at 30. The crystal parameters were adjusted at default values (Coordinates: Normal, Lattice Style: the same, Lattice: (1)). The results of the docking process were then visualized using Discovery Studio 4.0 software [71].

\subsection{Pharmacokinetic Profiling}

Pharmacokinetic profile of the compounds was determined using Discovery studio 4.0. [72]. 


\subsection{ADMET Analysis}

ADMET descriptors (absorption, distribution, metabolism, excretion and toxicity) of the compounds were determined using Discovery studio 4.0. At first, the CHARMM force field was applied, then the tested compounds were prepared and minimized according to the preparation of small molecule protocol. Then ADMET descriptors protocol was applied to carry out these studies [73].

\subsection{Toxicity Studies}

The toxicity parameters of the tested compounds were calculated using Discovery studio 4.0. Indinavir was used as a reference drug. At first, the CHARMM force field was applied then the compounds were prepared and minimized according to the preparation of small molecule protocol. Then different parameters were calculated from the toxicity prediction (extensible) protocol [73-75].

\subsection{DFT Studies}

The DFT parameters (total energy, binding energy, HOMO, LUMO, gap energy, dipole moment, and electrostatic potential) were calculated using Discovery studio software. The tested compounds were prepared using prepare ligand protocol. Then, the prepared compounds were subjected to DFT calculation protocol using the default option [76].

Supplementary Materials: The following are available online, Table S1: Detailed toxicity report, in addition to the method (Docking studies, ADMET studies, Toxicity studies and DFT studies).

Author Contributions: Conceptualization, A.M.M. and I.H.E.; methodology I.H.E. and M.S.A.; software. M.S.A., E.B.E. and I.H.E.; writing-review and editing, A.M.M., E.B.E., A.A.A. and I.H.E.; supervision, A.M.M. and I.H.E.; project administration, A.M.M. and I.H.E.; funding acquisition, E.B.E. All authors have read and agreed to the published version of the manuscript.

Funding: The authors extend their appreciation to the Research center at Almaarefa University for funding this work.

Institutional Review Board Statement: Not applicable.

Informed Consent Statement: Not applicable.

Data Availability Statement: Data is contained within the article.

Conflicts of Interest: The authors declare no conflict of interest.

Sample Availability: Samples of the compounds are not available from the authors.

\section{References}

1. WHO. WHO Coronavirus (COVID-19) Dashboard. Available online: https:/ / covid19.who.int/ (accessed on 10 September 2021).

2. Ekins, S.; Mestres, J.; Testa, B. In silico pharmacology for drug discovery: Applications to targets and beyond. Br. J. Pharmacol. 2007, 152, 21-37. [CrossRef]

3. Marrone, T.J.; Briggs, A.; James, M.; McCammon, J.A. Structure-based drug design: Computational advances. Annu. Rev. Pharmacol. Toxicol. 1997, 37, 71-90. [CrossRef] [PubMed]

4. Li, N.; Wang, Y.; Li, W.; Li, H.; Yang, L.; Wang, J.; Mahdy, H.A.; Mehany, A.; Jaiash, D.A.; Santali, E.Y. Screening of Some Sulfonamide and Sulfonylurea Derivatives as Anti-Alzheimer's Agents Targeting BACE1 and PPAR $\gamma$. J. Chem. 2020, 2020, 1631243. [CrossRef]

5. Abdel-Aziz, H.A.; Eldehna, W.M.; Fares, M.; Al-Rashood, S.T.; Al-Rashood, K.A.; Abdel-Aziz, M.M.; Soliman, D.H. Synthesis, biological evaluation and 2D-QSAR study of halophenyl bis-hydrazones as antimicrobial and antitubercular agents. Int. J. Mol. Sci. 2015, 16, 8719-8743. [CrossRef]

6. Yadav, D.K.; Khan, F.; Negi, A.S. Pharmacophore modeling, molecular docking, QSAR, and in silico ADMET studies of gallic acid derivatives for immunomodulatory activity. J. Mol. Model. 2012, 18, 2513-2525. [CrossRef] [PubMed]

7. Zhang, W.; Pei, J.; Lai, L. Computational multitarget drug design. J. Chem. Inf. Model. 2017, 57, 403-412. [CrossRef]

8. Youssef, M.I.; Zhou, Y.; Eissa, I.H.; Wang, Y.; Zhang, J.; Jiang, L.; Hu, W.; Qi, J.; Chen, Z. Tetradecyl 2, 3-dihydroxybenzoate alleviates oligodendrocyte damage following chronic cerebral hypoperfusion through IGF-1 receptor. Neurochem. Int. 2020, 138, 104749. [CrossRef] 
9. Hadni, H.; Elhallaoui, M. 2D and 3D-QSAR, molecular docking and ADMET properties in silico studies of azaaurones as antimalarial agents. New J. Chem. 2020, 44, 6553-6565. [CrossRef]

10. El-Metwally, S.A.; Abou-El-Regal, M.M.; Eissa, I.H.; Mehany, A.B.; Mahdy, H.A.; Elkady, H.; Elwan, A.; Elkaeed, E.B. Discovery of thieno [2, 3-d] pyrimidine-based derivatives as potent VEGFR-2 kinase inhibitors and anti-cancer agents. Bioorg. Chem. 2021, 112, 104947. [CrossRef]

11. Alanazi, M.M.; Eissa, I.H.; Alsaif, N.A.; Obaidullah, A.J.; Alanazi, W.A.; Alasmari, A.F.; Albassam, H.; Elkady, H.; Elwan, A. Design, synthesis, docking, ADMET studies, and anticancer evaluation of new 3-methylquinoxaline derivatives as VEGFR-2 inhibitors and apoptosis inducers. J. Enzym. Inhib. Med. Chem. 2021, 36, 1760-1782. [CrossRef]

12. Alanazi, M.M.; Alaa, E.; Alsaif, N.A.; Obaidullah, A.J.; Alkahtani, H.M.; Al-Mehizia, A.A.; Alsubaie, S.M.; Taghour, M.S.; Eissa, I.H. Discovery of new 3-methylquinoxalines as potential anti-cancer agents and apoptosis inducers targeting VEGFR-2: Design, synthesis, and in silico studies. J. Enzym. Inhib. Med. Chem. 2021, 36, 1732-1750. [CrossRef] [PubMed]

13. Alsaif, N.A.; Taghour, M.S.; Alanazi, M.M.; Obaidullah, A.J.; Al-Mehizia, A.A.; Alanazi, M.M.; Aldawas, S.; Elwan, A.; Elkady, H. Discovery of new VEGFR-2 inhibitors based on bis ([1, 2, 4] triazolo)[4, 3-a: 3', 4'-c] quinoxaline derivatives as anticancer agents and apoptosis inducers. J. Enzym. Inhib. Med. Chem. 2021, 36, 1093-1114. [CrossRef] [PubMed]

14. Alsaif, N.A.; Dahab, M.A.; Alanazi, M.M.; Obaidullah, A.J.; Al-Mehizia, A.A.; Alanazi, M.M.; Aldawas, S.; Mahdy, H.A.; Elkady, H. New quinoxaline derivatives as VEGFR-2 inhibitors with anticancer and apoptotic activity: Design, molecular modeling, and synthesis. Bioorg. Chem. 2021, 110, 104807. [CrossRef]

15. El-Adl, K.; Ibrahim, M.-K.; Alesawy, M.S.; Eissa, I.H. [1, 2, 4] Triazolo [4, 3-c] quinazoline and bis ([1, 2, 4] triazolo)[4, 3-a: $4^{\prime}$, 3'-c] quinazoline derived DNA intercalators: Design, synthesis, in silico ADMET profile, molecular docking and anti-proliferative evaluation studies. Bioorg. Med. Chem. 2021, 30, 115958. [CrossRef]

16. Parmar, D.R.; Soni, J.Y.; Guduru, R.; Rayani, R.H.; Kusurkar, R.V.; Vala, A.G.; Talukdar, S.N.; Eissa, I.H.; Metwaly, A.M.; Khalil, A. Discovery of new anticancer thiourea-azetidine hybrids: Design, synthesis, in vitro antiproliferative, SAR, in silico molecular docking against VEGFR-2, ADMET, toxicity, and DFT studies. Bioorg. Chem. 2021, 115, 105206. [CrossRef]

17. Jalmakhanbetova, R.I.; Suleimen, Y.M.; Oyama, M.; Elkaeed, E.B.; Eissa, I.; Suleimen, R.N.; Metwaly, A.M.; Ishmuratova, M.Y. Isolation and In Silico Anti-COVID-19 Main Protease (Mpro) Activities of Flavonoids and a Sesquiterpene Lactone from Artemisia sublessingiana. J. Chem. 2021, 2021, 5547013. [CrossRef]

18. Al-Karmalawy, A.A.; Dahab, M.A.; Metwaly, A.M.; Elhady, S.S.; Elkaeed, E.B.; Eissa, I.H.; Darwish, K.M. Molecular Docking and Dynamics Simulation Revealed the Potential Inhibitory Activity of ACEIs Against SARS-CoV-2 Targeting the hACE2 Receptor. Front. Chem. 2021, 9, 661230. [CrossRef]

19. Alesawy, M.S.; Abdallah, A.E.; Taghour, M.S.; Elkaeed, E.B.; Eissa, I.H.; Metwaly, A.M. In Silico Studies of Some Isoflavonoids as Potential Candidates against COVID-19 Targeting Human ACE2 (hACE2) and Viral Main Protease (Mpro). Molecules 2021, 26, 2806. [CrossRef]

20. El-Demerdash, A.; Metwaly, A.M.; Hassan, A.; El-Aziz, A.; Mohamed, T.; Elkaeed, E.B.; Eissa, I.H.; Arafa, R.K.; Stockand, J.D. Comprehensive virtual screening of the antiviral potentialities of marine polycyclic guanidine alkaloids against SARS-CoV-2 (COVID-19). Biomolecules 2021, 11, 460. [CrossRef] [PubMed]

21. Imieje, V.O.; Zaki, A.A.; Metwaly, A.M.; Mostafa, A.E.; Elkaeed, E.B.; Falodun, A. Comprehensive In Silico Screening of the Antiviral Potentialities of a New Humulene Glucoside from Asteriscus hierochunticus against SARS-CoV-2. J. Chem. 2021, 2021, 5541876. [CrossRef]

22. Metwaly, A.M.; Ghoneim, M.M.; Eissa, I.H.; Elsehemy, I.A.; Mostafa, A.E.; Hegazy, M.M.; Afifi, W.M.; Dou, D. Traditional ancient Egyptian medicine: A review. Saudi J. Biol. Sci. 2021, 28, 5823-5832. [CrossRef] [PubMed]

23. Han, X.; Yang, Y.; Metwaly, A.M.; Xue, Y.; Shi, Y.; Dou, D. The Chinese herbal formulae (Yitangkang) exerts an antidiabetic effect through the regulation of substance metabolism and energy metabolism in type 2 diabetic rats. J. Ethnopharmacol. 2019, 239, 111942. [CrossRef]

24. Metwaly, A.M.; Lianlian, Z.; Luqi, H.; Deqiang, D. Black ginseng and its saponins: Preparation, phytochemistry and pharmacological effects. Molecules 2019, 24, 1856. [CrossRef]

25. Wang, Y.-M.; Ran, X.-K.; Riaz, M.; Yu, M.; Cai, Q.; Dou, D.-Q.; Metwaly, A.M.; Kang, T.-G.; Cai, D.-C. Chemical constituents of stems and leaves of Tagetespatula L. and its fingerprint. Molecules 2019, 24, 3911. [CrossRef]

26. Metwaly, A. Comparative biological evaluation of four endophytic fungi isolated from nigella sativa seeds. Al-Azhar J. Pharm. Sci. 2019, 59, 123-136. [CrossRef]

27. Metwaly, A.M.; Wanas, A.S.; Radwan, M.M.; Ross, S.A.; ElSohly, M.A. New $\alpha$-Pyrone derivatives from the endophytic fungus Embellisia sp. Med. Chem. Res. 2017, 26, 1796-1800. [CrossRef]

28. Metwaly, A.M.; Ghoneim, M.M.; Musa, A. Two new antileishmanial diketopiperazine alkaloids from the endophytic fungus Trichosporum sp. Derpharmachemica 2015, 7, 322-327.

29. Ghoneim, M.M.; Afifi, W.M.; Ibrahim, M.; Elagawany, M.; Khayat, M.T.; Aboutaleb, M.H.; Metwaly, A.M. Biological evaluation and molecular docking study of metabolites from Salvadora Persica L. Growing in Egypt. Pharmacogn. Mag. $2019,15,232$.

30. Liu, L.; Luo, S.; Yu, M.; Metwaly, A.M.; Ran, X.; Ma, C.; Dou, D.; Cai, D. Chemical Constituents of Tagetes patula and Their Neuroprotecting Action. Nat. Prod. Commun. 2020, 15, 1-8. 
31. Yassin, A.M.; El-Deeb, N.M.; Metwaly, A.M.; El Fawal, G.F.; Radwan, M.M.; Hafez, E.E. Induction of apoptosis in human cancer cells through extrinsic and intrinsic pathways by Balanites aegyptiaca furostanol saponins and saponin-coated silvernanoparticles. Appl. Biochem. Biotechnol. 2017, 182, 1675-1693. [CrossRef] [PubMed]

32. Sharaf, M.H.; El-Sherbiny, G.M.; Moghannem, S.A.; Abdelmonem, M.; Elsehemy, I.A.; Metwaly, A.M.; Kalaba, M.H. New combination approaches to combat methicillin-resistant Staphylococcus aureus (MRSA). Sci. Rep. 2021, 11, 1-16. [CrossRef] [PubMed]

33. Suleimen, Y.M.; Metwaly, A.M.; Mostafa, A.E.; Elkaeed, E.B.; Liu, H.-W.; Basnet, B.B.; Suleimen, R.N.; Ishmuratova, M.Y.; Turdybekov, K.M.; Van Hecke, K. Isolation, Crystal Structure, and In Silico Aromatase Inhibition Activity of Ergosta-5, 22-dien3 $\beta$-ol from the Fungus Gyromitra esculenta. J. Chem. 2021, 2021, 5529786. [CrossRef]

34. Metwaly, A.M.; Kadry, H.A.; Atef, A.; Mohammad, A.-E.I.; Ma, G.; Cutler, S.J.; Ross, S.A. Nigrosphaerin A a new isochromene derivative from the endophytic fungus Nigrospora sphaerica. Phytochem. Lett. 2014, 7, 1-5. [CrossRef] [PubMed]

35. Metwaly, A.M.; Fronczek, F.R.; Ma, G.; Kadry, H.A.; Atef, A.; Mohammad, A.-E.I.; Cutler, S.J.; Ross, S.A. Antileukemic $\alpha$-pyrone derivatives from the endophytic fungus Alternaria phragmospora. Tetrahedron Lett. 2014, 55, 3478-3481. [CrossRef]

36. Zhanzhaxina, A.; Suleimen, Y.; Metwaly, A.M.; Eissa, I.H.; Elkaeed, E.B.; Suleimen, R.; Ishmuratova, M.; Akatan, K.; Luyten, W. In Vitro and In Silico Cytotoxic and Antibacterial Activities of a Diterpene from Cousinia alata Schrenk. J. Chem. 2021, 2021, 5542455. [CrossRef]

37. Imieje, V.O.; Zaki, A.A.; Metwaly, A.M.; Eissa, I.H.; Elkaeed, E.B.; Ali, Z.; Khan, I.A.; Falodun, A. Antileishmanial Derivatives of Humulene from Asteriscus hierochunticus with in silico Tubulin Inhibition Potential. Rec. Nat. Prod. 2021, 16, $150-171$.

38. Jalmakhanbetova, R.; Elkaeed, E.B.; Eissa, I.H.; Metwaly, A.M.; Suleimen, Y.M. Synthesis and Molecular Docking of Some Grossgemin Amino Derivatives as Tubulin Inhibitors Targeting Colchicine Binding Site. J. Chem. 2021, 2021, 5586515. [CrossRef]

39. Newman, D.J.; Cragg, G.M. Natural products as sources of new drugs from 1981 to 2014. J. Nat. Prod. 2016, 79, 629-661. [CrossRef]

40. da Rosa, R.; Schenkel, E.P.; Bernardes, L.S.C. Semisynthetic and newly designed derivatives based on natural chemical scaffolds: Moving beyond natural products to fight Trypanosoma cruzi. Phytochem. Rev. 2020, 19, 105-122. [CrossRef]

41. Sánchez-Recillas, A.; Navarrete-Vázquez, G.; Hidalgo-Figueroa, S.; Rios, M.Y.; Ibarra-Barajas, M.; Estrada-Soto, S. Semisynthesis, ex vivo evaluation, and SAR studies of coumarin derivatives as potential antiasthmatic drugs. Eur. J. Med. Chem. 2014, 77, 400-408. [CrossRef] [PubMed]

42. Shin, D.; Mukherjee, R.; Grewe, D.; Bojkova, D.; Baek, K.; Bhattacharya, A.; Schulz, L.; Widera, M.; Mehdipour, A.R.; Tascher, G.; et al. Papain-like protease regulates SARS-CoV-2 viral spread and innate immunity. Nature 2020, 587, 657-662. [CrossRef]

43. Báez-Santos, Y.M.; John, S.E.S.; Mesecar, A.D. The SARS-coronavirus papain-like protease: Structure, function and inhibition by designed antiviral compounds. Antivir. Res. 2015, 115, 21-38. [CrossRef]

44. Ratia, K.; Pegan, S.; Takayama, J.; Sleeman, K.; Coughlin, M.; Baliji, S.; Chaudhuri, R.; Fu, W.; Prabhakar, B.S.; Johnson, M.E. A noncovalent class of papain-like protease/deubiquitinase inhibitors blocks SARS virus replication. Proc. Natl. Acad. Sci. USA 2008, 105, 16119-16124. [CrossRef] [PubMed]

45. Báez-Santos, Y.M.; Barraza, S.J.; Wilson, M.W.; Agius, M.P.; Mielech, A.M.; Davis, N.M.; Baker, S.C.; Larsen, S.D.; Mesecar, A.D. $\mathrm{X}$-ray structural and biological evaluation of a series of potent and highly selective inhibitors of human coronavirus papain-like proteases. J. Med. Chem. 2014, 57, 2393-2412. [CrossRef] [PubMed]

46. Osipiuk, J.; Azizi, S.-A.; Dvorkin, S.; Endres, M.; Jedrzejczak, R.; Jones, K.A.; Kang, S.; Kathayat, R.S.; Kim, Y.; Lisnyak, V.G. Structure of papain-like protease from SARS-CoV-2 and its complexes with non-covalent inhibitors. Nat. Commun. 2021, 12, 1-9. [CrossRef] [PubMed]

47. Abdallah, A.E.; Alesawy, M.S.; Eissa, S.I.; El-Fakharany, E.M.; Kalaba, M.H.; Sharaf, M.H.; Shama, N.M.A.; Mahmoud, S.H.; Mostafa, A.; Al-Karmalawy, A.A.; et al. Design and synthesis of new 4-(2-nitrophenoxy) benzamide derivatives as potential antiviral agents: Molecular modeling and in vitro antiviral screening. New J. Chem. 2021, 45, 16557-16571. [CrossRef]

48. Rut, W.; Lv, Z.; Zmudzinski, M.; Patchett, S.; Nayak, D.; Snipas, S.J.; Oualid, F.E.; Huang, T.T.; Bekes, M.; Drag, M.; et al. Activity profiling and crystal structures of inhibitor-bound SARS-CoV-2 papain-like protease: A framework for anti-COVID-19 drug design. Sci. Adv. 2020, 6, eabd4596. [CrossRef]

49. Laboratory, E. Natural-Product-Based Library. Available online: https:/ / eximedlab.com/Screening-Compounds.html (accessed on 11 August 2021).

50. Veber, D.F.; Johnson, S.R.; Cheng, H.-Y.; Smith, B.R.; Ward, K.W.; Kopple, K.D. Molecular properties that influence the oral bioavailability of drug candidates. J. Med. Chem. 2002, 45, 2615-2623. [CrossRef]

51. Lipinski, C.A.; Lombardo, F.; Dominy, B.W.; Feeney, P.J. Experimental and computational approaches to estimate solubility and permeability in drug discovery and development settings. Adv. Drug Deliv. Rev. 1997, 23, 3-25. [CrossRef]

52. Xia, X.; Maliski, E.G.; Gallant, P.; Rogers, D. Classification of kinase inhibitors using a Bayesian model. J. Med. Chem. 2004, 47, 4463-4470. [CrossRef]

53. BIOVIA. QSAR, ADMET and Predictive Toxicology. Available online: https://www.3dsbiovia.com/products/collaborativescience/biovia-discovery-studio/qsar-admet-and-predictive-toxicology.html (accessed on 11 September 2021).

54. Venkatapathy, R.; Wang, N.C.Y.; Martin, T.M.; Harten, P.F.; Young, D. Structure-Activity Relationships for Carcinogenic Potential. Gen. Appl. Syst. Toxicol. 2009. [CrossRef]

55. Goodrnan, G.; Wilson, R. Comparison of the dependence of the TD50 on maximum tolerated dose for mutagens and nonmutagens. Risk Anal. 1992, 12, 525-533. [CrossRef] 
56. Council, N.R. Correlation between carcinogenic potency and the maximum tolerated dose: Implications for risk assessment. In Issues in Risk Assessment; National Academies Press (US): Washington, DC, USA, 1993.

57. Gonella Diaza, R.; Manganelli, S.; Esposito, A.; Roncaglioni, A.; Manganaro, A.; Benfenati, E. Comparison of in silico tools for evaluating rat oral acute toxicity. SAR QSAR Environ. Res. 2015, 26, 1-27. [CrossRef] [PubMed]

58. Pizzo, F.; Benfenati, E. In silico models for repeated-dose toxicity (RDT): Prediction of the no observed adverse effect level (NOAEL) and lowest observed adverse effect level (LOAEL) for drugs. In In Silico Methods for Predicting Drug Toxicity; Springer: Berlin/Heidelberg, Germany, 2016; pp. 163-176.

59. Venkatapathy, R.; Moudgal, C.J.; Bruce, R.M. Assessment of the oral rat chronic lowest observed adverse effect level model in TOPKAT, a QSAR software package for toxicity prediction. J. Chem. Inf. Comput. Sci. 2004, 44, 1623-1629. [CrossRef] [PubMed]

60. Wilhelmus, K.R. The Draize eye test. Surv. Ophthalmol. 2001, 45, 493-515. [CrossRef]

61. Bosshard, E. Review on skin and mucous-membrane irritation tests and their application. Food Chem. Tox. 1985, 23, 149-154. [CrossRef]

62. Subashchandrabose, S.; Saleem, H.; Erdogdu, Y.; Rajarajan, G.; Thanikachalam, V. FT-Raman, FT-IR spectra and total energy distribution of 3-pentyl-2, 6-diphenylpiperidin-4-one: DFT method. Spectrochim. Acta Part A Mol. Biomol. Spectrosc. 2011, 82, 260-269. [CrossRef] [PubMed]

63. Huerta-Aguilar, C.A.; Palos-Barba, V.; Thangarasu, P.; Koodali, R.T. Visible light driven photo-degradation of Congo red by TiO2ZnO/Ag: DFT approach on synergetic effect on band gap energy. Chemosphere 2018, 213, 481-497. [CrossRef] [PubMed]

64. Mohammed, H.S.; Tripathi, V.D.; Darghouth, A.A. Synthesis, Characterization, DFT calculation and Antimicrobial Activity of Co (II) and $\mathrm{Cu}$ (II) complexes with azo dye. In Journal of Physics: Conference Series; IOP Publishing: Bristol, UK, 2019 ; p. 052051.

65. Fleming, I. Frontier Orbitals and Organic Chemical Reactions; Wiley: Hoboken, NJ, USA, 1977.

66. El-Nahass, M.; Kamel, M.; El-Deeb, A.; Atta, A.; Huthaily, S. Ab initio HF, DFT and experimental (FT-IR) investigation of vibrational spectroscopy of PN, N-dimethylaminobenzylidenemalononitrile (DBM). Spectrochim. Acta Part A Mol. Biomol. Spectrosc. 2011, 79, 443-450. [CrossRef]

67. Aihara, J.-I. Correlation found between the HOMO-LUMO energy separation and the chemical reactivity at the most reactive site for isolated-pentagon isomers of fullerenes. Phys. Chem. Chem. Phys. 2000, 2, 3121-3125. [CrossRef]

68. Suhasini, M.; Sailatha, E.; Gunasekaran, S.; Ramkumaar, G. Vibrational and electronic investigations, thermodynamic parameters, HOMO and LUMO analysis on Lornoxicam by density functional theory. J. Mol. Struct. 2015, 1100, 116-128. [CrossRef]

69. Bitencourt-Ferreira, G.; de Azevedo Junior, W.F. Electrostatic Potential Energy in Protein-Drug Complexes. Curr. Med. Chem. 2021, 28, 4954-4971. [CrossRef] [PubMed]

70. Matin, M.M.; Hasan, M.S.; Uzzaman, M.; Bhuiyan, M.M.H.; Kibria, S.M.; Hossain, M.E.; Roshid, M.H. Synthesis, spectroscopic characterization, molecular docking, and ADMET studies of mannopyranoside esters as antimicrobial agents. J. Mol. Struct. 2020, 1222, 128821. [CrossRef]

71. X-ray Structural and Biological Evaluation of a Series of Potent and Highly Selective Inhibitors of Human Coronavirus Papain-like Proteases. 2021. Available online: https://www.rcsb.org/structure/4OW0 (accessed on 11 September 2021).

72. El-Gamal, K.M.; El-Morsy, A.M.; Saad, A.M.; Eissa, I.H.; Alswah, M. Synthesis, docking, QSAR, ADMET and antimicrobial evaluation of new quinoline-3-carbonitrile derivatives as potential DNA-gyrase inhibitors. J. Mol. Struct. 2018, 1166, 15-33. [CrossRef]

73. Yousef, R.; Sakr, H.; Eissa, I.; Mehany, A.; Metwaly, A.; Elhendawy, M.A.; Radwan, M.; ElSohly, M.A.; Abulkhair, H.S.; El-Adl, K. New quinoxaline-2 $(1 \mathrm{H})$-ones as potential VEGFR-2 inhibitors: Design, synthesis, molecular docking, ADMET profile and anti-proliferative evaluations. New J. Chem. 2021, 45, 16949-16964. [CrossRef]

74. Amer, H.H.; Alotaibi, S.H.; Trawneh, A.H.; Metwaly, A.M.; Eissa, I.H. Anticancer activity, spectroscopic and molecular docking of some new synthesized sugar hydrazones, Arylidene and $\alpha$-Aminophosphonate derivatives. Arab. J. Chem. 2021, 14, 103348. [CrossRef]

75. Alesawy, M.S.; Al-Karmalawy, A.A.; Elkaeed, E.B.; Alswah, M.; Belal, A.; Taghour, M.S.; Eissa, I.H. Design and discovery of new 1, 2, 4-triazolo [4, 3-c] quinazolines as potential DNA intercalators and topoisomerase II inhibitors. Arch. Der Pharm. 2021, 354, 2000237. [CrossRef] [PubMed]

76. Eissa, I.H.; Khalifa, M.M.; Elkaeed, E.B.; Hafez, E.E.; Alsfouk, A.A.; Metwaly, A.M. In Silico Exploration of Potential Natural Inhibitors against SARS-CoV-2 nsp10. Molecules 2021, 26, 6151. [CrossRef] 